\title{
A COGNITIVE INTERFERENCE MODEL OF SEXUAL FUNCTIONING FOR GAY MEN: THE RELATIONSHIP BETWEEN INTERNALIZED HOMOPHOBIA AND ERECTILE FUNCTION
}

by

Natalie L. Stratton

Bachelor of Arts, Concordia University, Montreal, Quebec, 2010

\author{
A thesis \\ presented to Ryerson University \\ in partial fulfillment of the \\ requirements for the degree of \\ Master of Arts \\ in the Program of \\ Psychology \\ Toronto, Ontario, Canada, 2014 \\ (C) Natalie L. Stratton 2014
}




\section{AUTHOR'S DECLARATION FOR ELECTRONIC SUBMISSION OF A THESIS}

I hereby declare that I am the sole author of this thesis. This is a true copy of the thesis, including any required final revisions, as accepted by my examiners.

I authorize Ryerson University to lend this thesis to other institutions or individuals for the purpose of scholarly research.

I further authorize Ryerson University to reproduce this thesis by photocopying or by other means, in total or in part, at the request of other institutions or individuals for the purpose of scholarly research.

I understand that my thesis may be made electronically available to the public. 


\begin{abstract}
A Cognitive Interference Model Of Sexual Functioning For Gay Men: The Relationship Between Internalized Homophobia And Erectile Function

Master of Arts, 2014

Natalie L. Stratton

Clinical Psychology, Ryerson University

Gay men more frequently report erectile difficulties than heterosexual men, possibly due to the additional stress gay men experience as a result of their sexual minority status. Internalized homophobia (IH), defined as the internalization of negative societal attitudes about being gay, is associated with adverse sexual outcomes. However, the mechanisms underlying this relationship remain unclear. According to Barlow's model of sexual dysfunction, cognitive interference plays a key role in the development and maintenance of erectile dysfunction. The present study examined the cross-sectional and longitudinal relationships between $\mathrm{IH}$, cognitive anxiety symptoms, and erectile function in a sample of 252 HIV-negative gay and bisexual men. Participants completed a battery of self-report questionnaires assessing internalized homophobia, cognitive anxiety symptoms, and erectile functioning at baseline, 3-month, and 6-month followups. Cognitive anxiety symptoms did not mediate the relationship between IH and erectile function at baseline or across 6-months. Limitations and future directions are discussed.
\end{abstract}




\section{Acknowledgments}

First and foremost, I would like to thank my supervisor, Dr. Trevor Hart, for his incredible support. He is my biggest cheerleader and his commitment to my development has been critical to my growth as both a graduate student and researcher. I would also like to thank Dr. Tae Hart for their guidance and constructive feedback, which greatly improved the quality of my thesis. I am also grateful that Dr. Michelle Dionne agreed to be apart of my examining committee. As well, I would like to thank my fellow colleagues in the HIV Prevention Laboratory, including Amy Willis, Amrita Ghai, Anne Wagner, Danielle Schwartz, Tyler Tulloch, and Marie Faaborg-Andersen. It is a pleasure to work with such a wonderful group of people. I am also grateful to be a part of an amazingly encouraging and collegial cohort. A huge thank you to my husband, JCF, for being my source of happiness and motivation as well as my own personal therapist. Finally, I would like to acknowledge the Canadian Institutes for Health Research (CIHR) and the Ontario Graduate Scholarship who supported my Masters research. 


\section{Table of Contents}

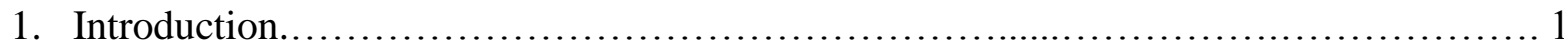

Minority stress....................................................... 5

Internalized homophobia and sexual functioning........................... 6

Theories of erectile dysfunction........................................ 7

Purpose and hypotheses............................................ 10

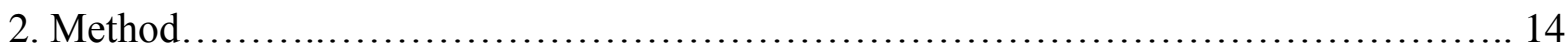

Participants......................................................... 14

Procedures........................................................... 18

Measures.............................................................. 18

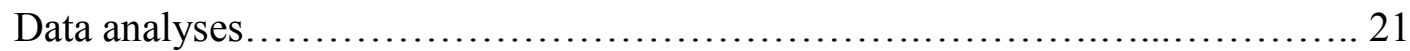

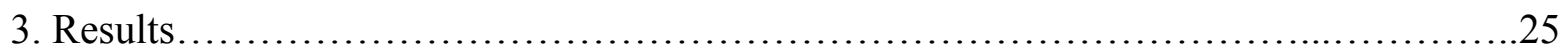

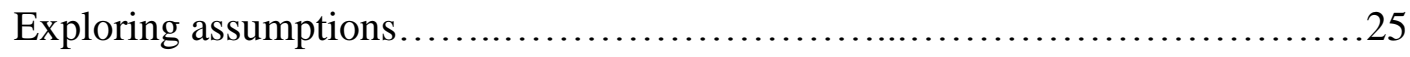

Descriptive statistics................................................25

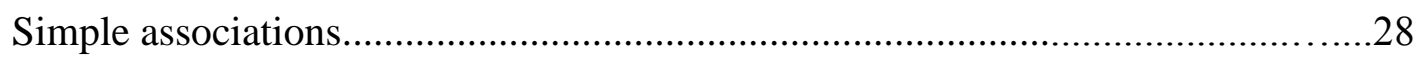

Simple mediation model................................................ 28

4. Discussion............................................................. 35

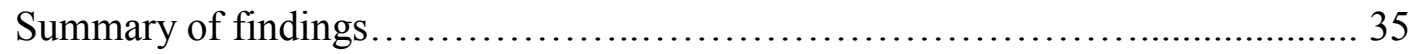

Limitations....................................................... 40

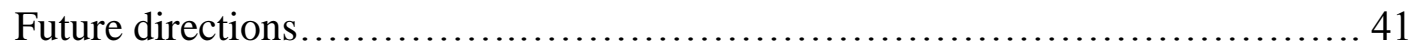

Implications..................................................... 45

Conclusion........................................................ 46

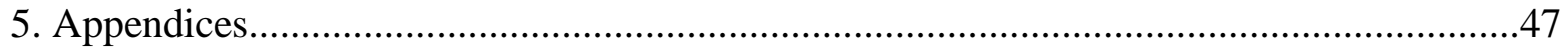




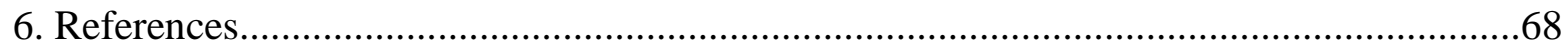




\section{List of Tables}

Table 1: Sociodemographic Characteristics and Comparisons of Included and Removed

Participants................................................................... 16

Table 2: Skewness and Kurtosis of the Study Variables..................................24

Table 3: Severity of Erectile Dysfunction (using Shindel et al., 2012)......................27

Table 4: Correlations between Internalized Homophobia, Cognitive Anxiety Symptoms, and

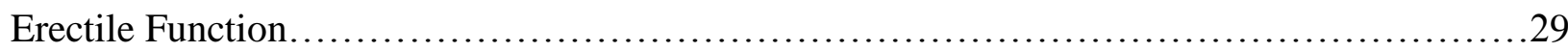

Table 5: Unstandardized Path Coefficients for the Cross-Sectional Mediation Model...........30

Table 6: Unstandardized Path Coefficients for the Longitudinal Mediation Model.............33 


\section{List of Figures}

Figure 1: Cross-sectional mediation model.........................................12

Figure 2: Longitudinal mediation model.........................................13

Figure 3: Path coefficients for cross-sectional mediation model.........................31

Figure 4: Path coefficients for longitudinal mediation model................................. 


\section{List of Appendices}

Appendix A: Recruitment Materials................................................47

Appendix B: Study Questionnaires.............................................53

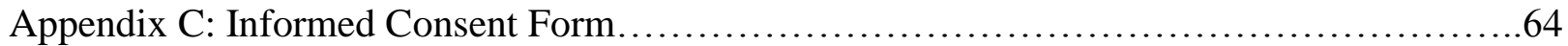

Appendix D: Debriefing Form................................................67 
A Cognitive Interference Model Of Sexual Functioning For Gay Men: The Relationship Between Internalized Homophobia And Erectile Function

Sexuality, which refers to the way individuals experience and express themselves as sexual beings (Rathus, Nevid, Fichner-Rathus, Herold, \& McKenzie, 2007), is an important component of an individual's quality of life (e.g., Davison, Bell, LaChina, Holden, \& Davis, 2009; McCabe \& Cummins, 1997). A central aspect of sexuality is an individual's sexual response. Pioneering sex researchers Masters and Johnson (1966) were the first to record physiological data from the human body and sex organs during sexual behaviour. Based on their observations of healthy sexual functioning adults, they proposed a human sexual response cycle that includes four stages: excitement, plateau, orgasm, and resolution (Masters \& Johnson, 1966). According to Masters and Johnson's model, sexual arousal develops during the excitement phase and progresses into full sexual arousal during the plateau stage (Masters \& Johnson, 1966). For men, physiological sexual arousal involves increased blood flow to the penis, resulting in erection (NIH, 2009). Orgasm, known as rhythmic contractions of the genitals and ejaculation in men, results from peaks in sexual arousal (Masters \& Johnson, 1966; Mah \& Binik, 2001). In addition to describing healthy sexual response patterns, Masters and Johnson's model is helpful in identifying disordered sexual functioning, in that sexual dysfunction arises when there is a disturbance at any phase of the sexual response cycle (American Psychiatric Association [APA], 2013). Erectile dysfunction, the primary focus of this thesis, is the result of a disturbance in one's ability to attain or maintain physiological sexual arousal, specifically erection (APA, 2013). Erectile dysfunction is not only common, but is also associated with a number of negative mental, physical, and social outcomes. 
National surveys assessing the prevalence of sexual dysfunction reveal that impaired sexual functioning is quite common. The National Health and Social Life Survey (NHSLS) reports that $31 \%$ of men between the ages of 18 and 59 years old experience some type of sexual dysfunction (Laumann et al., 1999). Similarly, the Global Study of Sexual Attitudes and Behaviours (GSSAB) indicates that, on average across five countries, $28 \%$ of men between the ages of 40 and 80 years old reported at least one sexual dysfunction (Nicolosi et al., 2006). Regarding erectile dysfunction, the Men's Attitudes to Life Events and Sexuality (MALES) study recruited men from eight countries (i.e., United States, Mexico, Brazil, United Kingdom, Germany, France, Italy, Spain) and found an overall prevalence of self-reported erectile dysfunction of $16 \%$ (Rosen et al., 2004). An estimated $40 \%$ to 50\% of men above the age of 60 years experience significant erectile difficulties, whereas only $2 \%$ of men below the age of 40 report frequent erectile difficulties (APA, 2013). Likewise, findings from the Massachusetts Male Aging Study (MMAS) show that $8 \%$ of men aged 40 and 49 years report either moderate or complete erectile dysfunction compared to roughly $40 \%$ of men in their sixties (McKinlay, 2000).

Gay men experience a higher incidence of erectile dysfunction compared to heterosexual men (e.g., Bancroft, Carnes, Janssen, Goodrich, \& Long, 2005; Cove \& Boyle, 2002; Rosser, Metz, Bockting, \& Buroker, 1997). In a study examining the prevalence of erectile dysfunction among heterosexual and gay men between 18 and 81 years old, $57.8 \%$ of gay men reported experiencing erectile difficulties in their lifetime compared to $46.2 \%$ of heterosexual men (Bancroft et al., 2005). In a similar study, $40 \%$ of gay men reported experiencing difficulty attaining an erection and $46 \%$ endorsed experiencing difficulty maintaining an erection in their lifetime (Rosser et al., 1997). In contrast, 26\% of heterosexual men reported difficulties attaining 
an erection and $29 \%$ endorsed experiencing difficulty maintaining an erection during their lifetime (Rosser et al., 1997). Additionally, a study investigating the sexuality of medical students in North America found that $24 \%$ of gay male students experienced erectile dysfunction compared to $12 \%$ of heterosexual male students (Breyer et al., 2010).

Erectile dysfunction is associated with a variety of adverse mental, physical, and psychosocial outcomes. Men with poor sexual functioning report lower objective (e.g., absence of a medical problem) and subjective (i.e., self-reported importance and satisfaction) quality of life across multiple domains, including health, intimacy, and emotional well-being, compared to men with good sexual functioning (McCabe, 1997). In the NHSLS, men with erectile dysfunction reported lower physical and emotional satisfaction as well as lower general happiness than men without sexual dysfunction (Laumann, Paik, \& Rosen, 1999). Men with erectile dysfunction also report lower sexual self-efficacy (Latini et al., 2002) and greater depression and anxiety symptoms than men without erectile dysfunction (e.g., Araujo, Durante, Feldman, Goldstein, \& McKinlay, 1998; Corona et al., 2008; Latini et al., 2002). In addition, erectile dysfunction is a risk factor for the transmission of sexually transmitted infections (STIs), since erectile difficulties increase the likeliness that a man will not use or will remove a condom before the completion of intercourse (Graham et al., 2006; Yarber et al., 2007). In fact, men with erectile dysfunction report higher rates of STIs than their sexually healthy counterparts (Musacchio et al., 2006).

Erectile dysfunction also negatively affects the partners of those experiencing sexual difficulties (e.g., Fisher, Rosen, Eardley, Sand, \& Goldstein, 2005). Female partners of men experiencing erectile difficulties report lower desire, arousal, frequency of orgasm, and sexual satisfaction compared to before their partner developed erectile difficulties (Fisher et al., 2005). 
Furthermore, men experiencing erectile dysfunction report lower intimacy across many areas of the relationship, such as emotional, social, sexual, recreation, and intellectual domains (McCabe, 1997). The GSSAB, a study of 13,618 men across 29 countries, found that $82 \%$ of men agree or strongly agree with the statement, "satisfactory sex is essential to the maintenance of a relationship" (Nicolosi et al., 2006). In a longitudinal study, individuals who experienced a decrease in sexual satisfaction over an 18-month period also rated their relationship satisfaction lower at follow-up (Byers, 2005).

Considering the negative mental, physical, and psychosocial outcomes related to sexual dysfunction and the elevated prevalence rates among gay men, understanding the mechanisms that contribute to the development and maintenance of sexual dysfunction in gay men is important to the delineation of prevention and treatment programs for this higher risk population (e.g., Sandfort \& de Keizer, 2001; Wolitski \& Fenton, 2011). Researchers stress the importance of adopting a biopsychosocial perspective when considering the sexual health of gay men (e.g., Cove \& Boyle, 2002; Sandfort \& de Keizer, 2001; Shires \& Miller, 1998). The biopsychosocial model asserts that biological (e.g., hormones, genetics, physical functioning), psychological (e.g., emotions, thoughts, personality), and social factors (e.g., community, family, peers, culture, religion) play a significant role in the etiology and treatment of illness (Engel, 1977). Although biological risk factors for erectile dysfunction (e.g., age, HIV seropositivity, lower urinary tract symptoms) are similar for gay and heterosexual men (Shindel, Vittinghoff, \& Breyer, 2012), the psychosocial risk factors differ between these two groups. For instance, lesbian, gay, and bisexual individuals are more likely to experience depression and anxiety disorders (King et al., 2008), alcohol and substance use problems (King et al., 2008), and discriminating and stigmatizing events (Meyer, 2003) than their heterosexual counterparts. One possible explanation 
for the increased prevalence of erectile dysfunction among gay men may be due to the additional stress gay men experience due to their status as a sexual minority.

\section{Minority stress}

According to Meyer (1995, 2003), individuals who belong to a minority group, such as gay men, experience additive stress due to frequent discrimination and/or stigmatization related to their minority status. Meyer (1995) introduced the term "minority stress" to refer to the process by which societal stress negatively influences minority groups. Meyer (2003) describes four ways that minority stress affects gay men specifically. First, gay men may experience objectively stressful events, such as being physically attacked, which may be chronic or acute in duration. Second, gay men may anticipate rejection or discrimination causing them to become hypervigilant to possible cues of rejection or discrimination during social situations, specifically with individuals belonging to the dominant group. Third, gay men may experience an internal conflict between their sexual preference for men and social pressures to maintain a heterosexual identity, a phenomenon that is known as internalized homophobia. Lastly, gay men face the added concerns regarding whether to reveal their identity as a member of a stigmatized group. Gay men constantly confront decisions to disclose their sexual identity and may fear the possible discovery of their sexual orientation by others (Pachankis, 2007). Therefore, certain situations, where stigma-related cues are present or the likeliness of discovery is heightened, may trigger negative cognitive (e.g., preoccupation, hypervigilance) and affective (e.g., depression, anxiety) reactions within individuals with a concealable stigma (Pachankis, 2007). Due to these fears of negative evaluation or rejection, individuals with a concealable stigma may excessively attend to their social interactions and behaviour (Meyer, 2003; Pachankis \& Goldfried, 2006). Individuals 
with a concealed stigma also experience difficulty maintaining close relationships and often isolate themselves (Pachankis, 2007).

As a result of minority stress, gay men are at an increased risk of developing adverse mental and physical health conditions. Among gay men, high internalized homophobia is associated with lower self-esteem (e.g., Allen \& Oleson, 1999; Herek, Gillis, \& Cogan, 2009; Rowen \& Malcolm, 2003), greater shame (Allen \& Oleson, 1999), higher body image dissatisfaction (Kimmel \& Mahalik, 2005), more relationship problems (Frost \& Meyer, 2009), and more depression and anxiety symptoms (e.g., Igartua, Gill, \& Montoro, 2003; Herek et al., 2009; Newcomb \& Mustanski, 2010). In addition, gay men with higher internalized homophobia are uncomfortable disclosing their sexual orientation and tend to be disconnected from the gay community (e.g., Herek et al., 2009; Newcomb \& Mustanski, 2010). Gay men with higher internalized homophobia also report more sexual partners and are more likely to engage in unprotected anal intercourse, thus increasing their risk of contracting an STI (Hatzenbuehler, Nolen-Hoeksema, \& Erickson, 2008). Similarly, gay men with higher internalized homophobia reported low self-efficacy and more barriers to practicing safe sex (Herek \& Glunt, 1995). Beyond the aforementioned associations between internalized homophobia and a variety of psychological and behavioural outcomes, internalized homophobia also negatively impacts the sexual functioning of gay men.

\section{Internalized homophobia and sexual functioning}

Because internalized homophobia is associated with a variety of adverse mental health outcomes, it is not surprising that internalized homophobia also negatively impacts gay men's sexual experiences. Gay men who endorse greater internalized homophobia are more likely to report high sexual guilt (Rowen \& Malcolm, 2003), which may negatively impact their sexual 
functioning and satisfaction. Kuyper and Vanwesenbeeck (2011) found that gay men who hold negative beliefs about being gay rate their sexual satisfaction lower than gay men who embrace being gay. Moreover, in two separate studies, gay men with high internalized homophobia reported experiencing sexual dysfunction more often than gay men with low internalized homophobia (Kuyper \& Vanwesenbeeck, 2011; Meyer, 1995). Similarly, Meyer and Dean (1998) found that gay men with high internalized homophobia were approximately four times as likely to report sexual dysfunction than gay men with low internalized homophobia. Although these three studies assessed for dysfunction in desire, arousal, and orgasm, the authors did not specify the type of sexual dysfunctions experienced by gay men who endorsed high internalized homophobia. This lack of clarification limits the interpretation of the study findings, since researchers consistently demonstrate that the rate of certain sexual dysfunctions varies between gay and heterosexual men. For instance, gay men less frequently report premature ejaculation (e.g., Bancroft et al., 2005; Shires \& Miller, 1998) and more frequently report erectile difficulties than heterosexual men (e.g., Bancroft et al., 2005; Rosser et al., 1997).

Despite the association between internalized homophobia and sexual dysfunction among gay men, there is a paucity of research investigating possible mechanisms involved in this relationship. Theories of sexual arousal discuss a number of mechanisms involved in the development and maintenance of erectile dysfunction and may help elucidate the relationship between internalized homophobia and erectile dysfunction.

\section{Theories of erectile dysfunction}

Over the years, researchers investigated a number of possible mechanisms involved in the development and maintenance of erectile dysfunction. The role of anxiety is a key component of many models of sexual dysfunction (McCabe et al., 2010). Masters and Johnson (1970) 
emphasized the negative impact of performance anxiety in the development and maintenance of sexual arousal disorders, including erectile dysfunction. More specifically, Masters and Johnson (1970) asserted that fears of sexual inadequacy and focusing on oneself during sexual activity, rather than on erotic cues (i.e., "spectatoring"), interfere with the development of physiological sexual arousal. Kaplan (1974) expanded upon the ideas proposed by Masters and Johnson, positing that demands for sexual performance by one's partner as well as excessive need to please one's partner may activate performance-related anxiety. However, the empirical evidence suggests that anxiety does not always interfere with sexual functioning in men and can, in fact, facilitate sexual arousal (e.g., Barlow, Sakheim, \& Beck, 1983). For instance, the fear associated with the possibility of being caught enhances, rather than inhibits, sexual arousal in the instance of certain paraphilias, such as exhibitionism and voyeurism (e.g., Barlow et al., 1983; Beck \& Barlow, 1984). As a result, researchers began investigating the impact of anxiety on sexual arousal among men with good versus poor sexual functioning. In one study, men with good sexual functioning (i.e., absence of sexual dysfunction) experienced increased sexual arousal when instructed to focus on a partner who they were told was highly aroused, whereas men with poor sexual functioning exhibited decreased sexual arousal under the same conditions (Beck, Barlow, \& Sakheim, 1983). During qualitative interviews following the experiment, sexually dysfunctional men reported experiencing increased performance-related concerns when their partner was highly aroused. In contrast, the men with good sexual functioning explained that their partner's high arousal increased their own sexual arousal. Furthermore, men with good sexual functioning experienced a decrease in physiological sexual arousal when asked to complete a neutral distraction task, whereas men with poor sexual functioning reported no difference in physiological sexual arousal (Abrahamson, Barlow, Sakheim, Beck, \& Athanasiou, 
1985). Therefore, individuals with erectile dysfunction may focus on their erection or sexual performance, which detracts from their ability to attend to pleasurable sensations of sexual activity and consequently leads to a decrease in sexual arousal (Beck \& Barlow, 1984, 1986a, 1986b).

Based on the aforementioned findings, Barlow (1986) proposed that cognitive interference and anxiety interact to cause disordered sexual functioning. Barlow (1986) hypothesized that the somatic symptoms of anxiety may facilitate physiological sexual arousal, since these responses share similar bodily changes (e.g., increased heart rate, sweating). However, the cognitive component of anxiety, such as negative performance-related cognitions, may inhibit sexual functioning (Barlow, 1986). Consistent with minority stress theory (e.g., Meyer, 1995; Pachankis, 2007), gay men may be more likely to experience negative cognitions in sexual situations due to the activation of negative views regarding being gay and the greater risk of rejection or unfavorable evaluation. In a study of undergraduate students, gay male participants reported significantly more non-erotic cognitive distractions during sexual activity regarding body image, performance, and concerns over contracting an STI than the heterosexual male participants (Lacefield \& Negy, 2012). In comparison to heterosexual men, gay male participants experienced higher anxiety regarding these cognitive distractions as well as higher anxiety related to the feared consequences of being discovered engaging in sexual activity with another man (Lacefield \& Negy, 2012). Furthermore, in a study investigating erectile difficulties among gay and heterosexual men recruited from the community, Bancroft, Carnes, Janssen, Goodrich, and Long (2005) found that gay men reported significantly greater concerns about performance failure (e.g., fear of losing erection, concerns about pleasing the partner) than their heterosexual counterparts, regardless of whether they experienced erectile dysfunction. 
Therefore, higher cognitive anxiety symptoms during sexual activity among gay men may account for the higher prevalence of erectile dysfunction among gay men.

In sum, the cognitive component of anxiety plays an important role in the development and maintenance of erectile dysfunction (for a comprehensive review, see Cranston-Cuebas \& Barlow, 1990). However, the majority of the aforementioned studies only recruited heterosexual men, despite the higher prevalence rate of erectile dysfunction among gay men than heterosexual men (e.g., Bancroft et al., 2005; Cove \& Boyle, 2002; Rosser et al., 1997). The current theories of sexual arousal, therefore, neither accurately capture the experiences of gay men nor explain the increased prevalence of erectile dysfunction among gay men. In addition, many of the previous studies that included gay and heterosexual men reported small sample sizes and recruited college samples, decreasing the ability detect an effect and the generalizability of the study findings. Furthermore, no study to date has examined why gay men may be more likely to experience greater anxiety-provoking thoughts during sexual activity compared to heterosexual men. Expanding current theories of erectile dysfunction in order to capture the unique experiences of gay men is important for the development and implementation of interventions that accurately address the precipitating and maintaining mechanisms of erectile dysfunction for gay men.

\section{Purpose and hypotheses}

The present study proposes a psychosocial model of erectile dysfunction for gay men that incorporates theories of minority stress and male sexual arousal. Based on the minority stress literature, internalized homophobia increases negative cognitions (e.g., preoccupation, hypervigilance) and emotions (e.g., anxiety, depression) related to identifying as gay (e.g., Herek et al., 2009), and is associated with poor sexual functioning (e.g., Kuyper \& Vanwesenbeeck, 
2011). Similarly, engaging in sexual activity with another male may trigger negative cognitions and emotions among this stigmatized group (e.g., Pachankis, 2007), subsequently interfering with erectile function. Therefore, this study will examine the relationship between internalized homophobia, cognitive anxiety symptoms, and erectile functioning across three time points (i.e., baseline, 3-month follow-up, and 6-month follow-up). Previous research investigated these relationships separately using cross-sectional data. Assessing these variables across three time points will elucidate whether these relationships are temporal in nature. In order to address the limitations of previous studies, this study recruited a community sample of over 300 MSM from the Toronto metropolitan area to explore the following hypotheses.

Hypothesis 1. Internalized homophobia will be positively associated with cognitive anxiety symptoms and negatively associated with erectile function at baseline, 3-months, and 6months.

Hypothesis 2. Cognitive anxiety symptoms will be negatively associated with erectile function at baseline, 3-months, and 6-months.

Hypothesis 3. At baseline, cognitive anxiety symptoms will account for the relationship between internalized homophobia and erectile function. More specifically, internalized homophobia will reduce erectile function indirectly by increasing cognitive anxiety symptoms. Figure 1 depicts the cross-sectional model.

Hypothesis 4. Cognitive anxiety symptoms at 3-month follow-up will account for the relationship between baseline internalized homophobia and erectile function at 6-month followup. More specifically, higher baseline internalized homophobia will be associated with reduced erectile function at 6-month follow-up indirectly via increased cognitive anxiety symptoms at 3month follow-up. Figure 2 depicts the longitudinal model. 


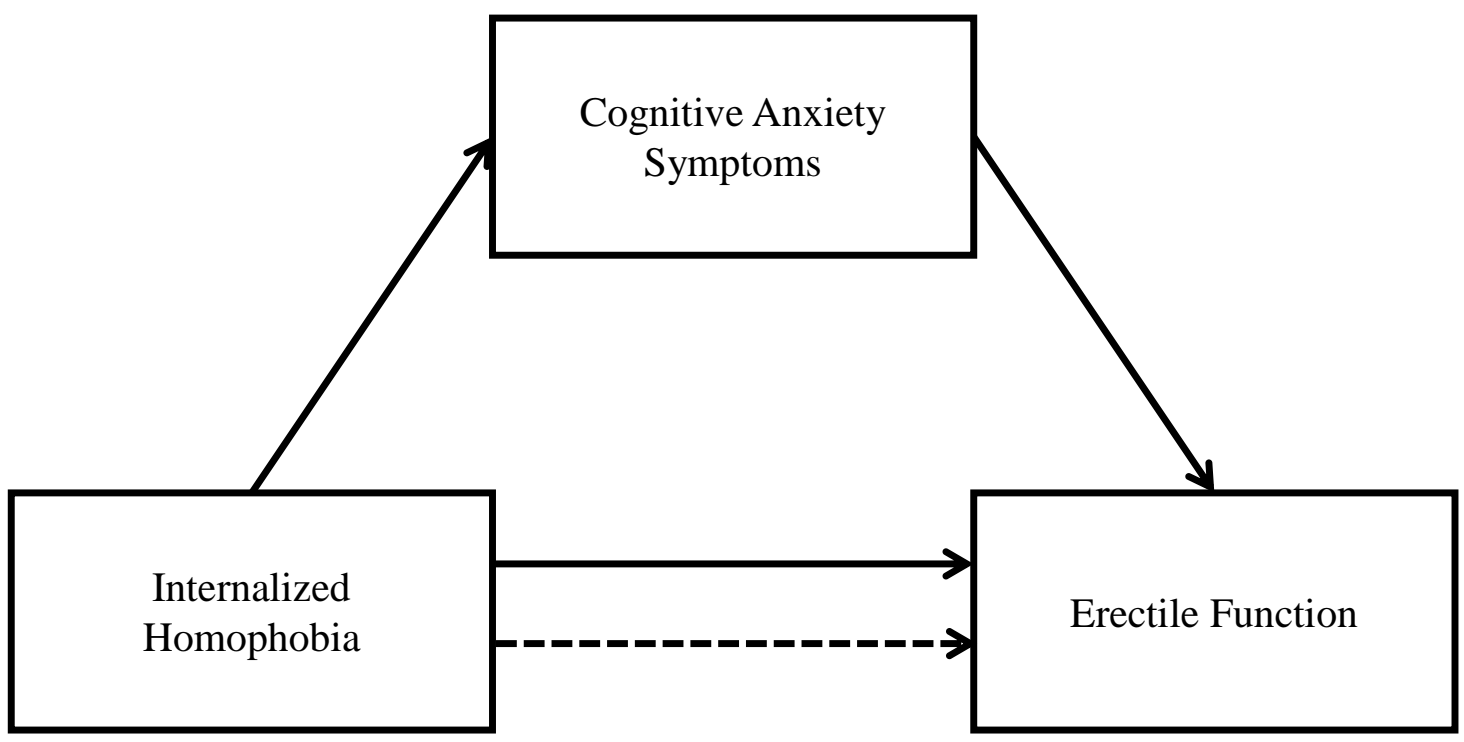

Figure 1. Cross-sectional mediation model. The dotted line depicts the $c$ ' path, which is the effect of internalized homophobia on erectile function when cognitive anxiety is not included as a mediator (i.e., direct effect). 


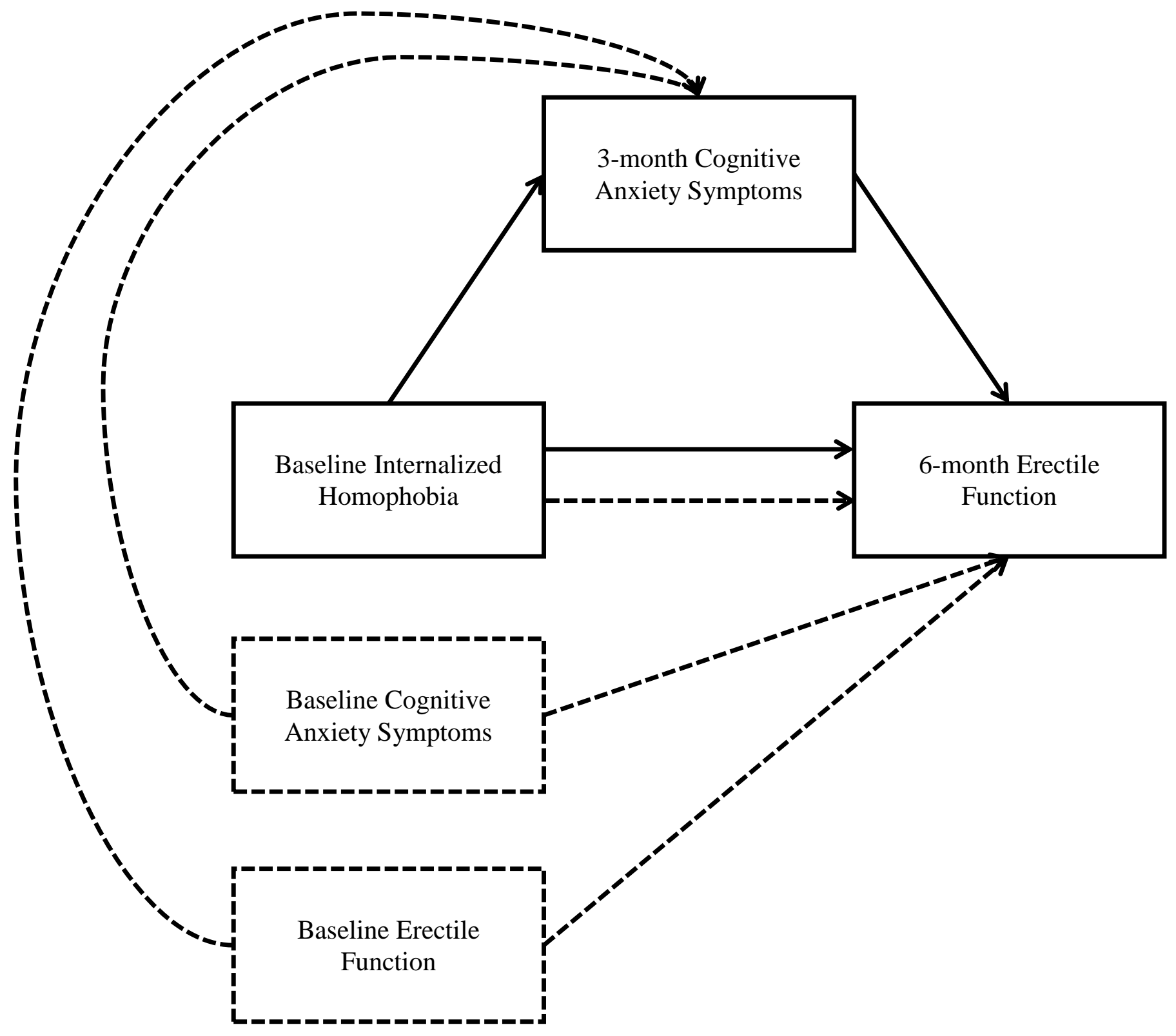

Figure 2. Longitudinal mediation model. The dotted lines depicts the $c$ ' path (i.e., direct effect) as well as the control variables. 


\section{Method}

\section{Participants}

This thesis is part of a larger ongoing study, called the Gay Strengths Study, which aims to recruit a total of $470 \mathrm{HIV}$-negative gay, bisexual, and other MSM in order to investigate protective factors and safer sex practices used by this population to avoid HIV infection. Participants were recruited through posters placed at venues (e.g., bars, bathhouses) and community organizations (e.g., AIDS service organizations) within the Toronto metropolitan area that have been previously identified as locations frequented by gay men (Adam, Husbands, Murray, \& Maxwell, 2008). In addition, electronic advertisements were placed on social media sites (Facebook) and websites targeting gay men (Squirt.org). Flyers were also distributed at community events, such as the Toronto Pride Street Festival (see Appendix A for all recruitment materials). There were several eligibility criteria for the larger study. First, participants needed to identify as male and report engaging in any type of sexual activity with another male during the past six months. Second, participants were eligible if they were over the age of 18 years old, able to speak and read in English, and anticipated being able to attend assessment sessions at all three time points (refer to the procedures section for more details regarding the assessment sessions). Third, participants were required to self-report an HIV-negative status. If a participant's HIV status changed during the course of the study, they were permitted to continue; however, their data were not used for this thesis, since the prevalence of erectile dysfunction is significantly higher among HIV-positive than HIV-negative men (e.g., Asboe et al., 2007; Cove \& Petrak, 2004; Ende, Re III, DiNubile, \& Mounzer, 2006). Finally, participants who reported experiencing symptoms of a severe psychological condition (e.g., major depression, bipolar disorder, schizophrenia) at the time of the telephone screening were ineligible for this study. 
The study hypotheses were evaluated using the available data from a subsample in order to allow for the data analyses to commence in January 2014. At that time, a total of 333 MSM completed the baseline assessment. Of the removed participants, 69 (20.7\%) did not attend all three assessment sessions and 5 (1.5\%) seroconverted during the course of the study. Data belonging to $7(2.1 \%)$ participants who endorsed either a transmale, two spirited, or queer gender identity were also not included, since the study's outcome variable is erectile function and we did not verify whether these participants possessed or identified with their anatomically male genitalia. The final sample included $252 \mathrm{MSM}$. Table 1 provides the demographic information for the sample. Prior to removing participants who identified as a transman, two spirited or queer, removed participants did not differ from the final sample on demographic variables, including gender, sexual orientation, ethnicity, education, annual income, and relationship status. In contrast, there was a significant relationship between completion status and both gender, $\chi^{2}(3)$ $=28.78, p<.01$, Cramer's $V=.29$, and sexual orientation, $\chi^{2}(5)=18.63, p<.01$, Cramer's $V=$ .24 following the removal of participants who did not endorse a male gender identity. In addition, removed participants were significantly younger $(M=33.92, S D=11.21)$ than the final analytic sample $(M=37.67, S D=12.91)$, both prior to, $t(331)=2.25, p<.05$, Cohen's $d=.31$, and after (see Table 1) the data belonging to participants who did not endorse a male gender identity were removed. This difference did not affect the study outcomes, since age was entered as a covariate due to its association with erectile function (e.g., Bancroft et al., 2005; Laumann et al., 1999; Laumann et al., 2007; Shindel et al., 2012). Removed participants did not differ on baseline measures of internalized homophobia, cognitive anxiety symptoms, and erectile function. 
Table 1

Sociodemographic Characteristics and Comparisons of Included and Removed Participants

\begin{tabular}{|c|c|c|c|}
\hline & $\begin{array}{l}\text { Included } \\
(n=252)\end{array}$ & $\begin{array}{l}\text { Removed } \\
(n=81)\end{array}$ & \\
\hline Variable & $n(\%)$ & $n(\%)$ & Test Statistic \\
\hline Gender & & & $\chi^{2}(3)=28.78 *$ \\
\hline Male & $252(100)$ & $72(88.9)$ & \\
\hline Transman & $0(0)$ & $4(4.9)$ & \\
\hline Two-spirited & $0(0)$ & $3(3.7)$ & \\
\hline Queer & $0(0)$ & $2(2.5)$ & \\
\hline Sexual Orientation & & & $\chi^{2}(5)=18.63 *$ \\
\hline Gay & $224(88.9)$ & $62(76.5)$ & \\
\hline Bisexual & $23(9.1)$ & $11(13.6)$ & \\
\hline Queer & $3(1.2)$ & $2(2.5)$ & \\
\hline Two-spirited & $0(0)$ & $3(3.7)$ & \\
\hline Pansexual & $1(0.4)$ & $2(2.5)$ & \\
\hline Undefined & $1(0.4)$ & $1(1.2)$ & \\
\hline Ethnicity & & & $\chi^{2}(6)=7.58$ \\
\hline White & $133(52.8)$ & $36(44.4)$ & \\
\hline Black & $16(6.3)$ & $8(9.9)$ & \\
\hline Latin American & $14(5.6)$ & $2(2.5)$ & \\
\hline South Asian & $15(6.0)$ & $5(6.2)$ & \\
\hline East/Southeast Asian & $18(7.1)$ & $3(3.7)$ & \\
\hline Middle Eastern & $6(2.4)$ & $2(2.5)$ & \\
\hline Two or more ethnicities & $50(19.8)$ & $25(30.9)$ & \\
\hline Highest Education & & & $\chi^{2}(6)=2.64$ \\
\hline Did not attend high school & $1(0.4)$ & $1(1.2)$ & \\
\hline Some high school & $7(2.8)$ & $4(4.9)$ & \\
\hline Completed high school & $14(5.6)$ & $6(7.4)$ & \\
\hline Some secondary education & $64(25.4)$ & $20(24.7)$ & \\
\hline $\begin{array}{l}\text { Completed secondary } \\
\text { education }\end{array}$ & $103(40.9)$ & $30(37.0)$ & \\
\hline $\begin{array}{l}\text { Some graduate or professional } \\
\text { school }\end{array}$ & $17(6.7)$ & $7(8.6)$ & \\
\hline $\begin{array}{l}\text { Completed graduate or } \\
\text { professional school }\end{array}$ & $46(18.3)$ & $13(16.0)$ & \\
\hline Annual Income & & & $\chi^{2}(4)=2.78$ \\
\hline Under $\$ 20000$ & $89(35.3)$ & $35(43.2)$ & \\
\hline$\$ 20000-\$ 39999$ & $70(27.8)$ & $20(24.7)$ & \\
\hline$\$ 40000-\$ 59999$ & $44(17.5)$ & $15(18.5)$ & \\
\hline$\$ 60000$ - \$79 999 & $26(10.3)$ & $7(8.6)$ & \\
\hline Over $\$ 80000$ & $23(9.1)$ & $4(4.9)$ & \\
\hline
\end{tabular}




\begin{tabular}{|c|c|c|c|}
\hline & \multirow[t]{3}{*}{$\chi^{2}(1)=0.60$} \\
\hline Single & $154(61.1)$ & $45(56.2)$ & \\
\hline \multirow[t]{2}{*}{ Partnered } & $98(38.9)$ & $35(43.8)$ & \\
\hline & $M(S D)$ & $M(S D)$ & \\
\hline Age & $37.88(12.97)$ & $33.62(11.02)$ & $t(157.07)=2.90 *$ \\
\hline Internalized Homophobia & $15.04(6.60)$ & $15.99(8.01)$ & $t(113.09)=-0.96$ \\
\hline Cognitive Anxiety Symptoms & $20.20(6.30)$ & $21.17(6.77)$ & $t(331)=-1.18$ \\
\hline Erectile Function & $19.88(6.90)$ & $20.38(7.28)$ & $t(325)=-0.54$ \\
\hline
\end{tabular}

Note. Participants' data were removed if they did not attend all three assessment sessions, seroconverted during the course of the study, or endorsed a transmale, two spirited, or queer gender identity. All measures reported are baseline values.

$* p<.05$ 


\section{Procedures}

Interested participants contacted the HIV Prevention Lab via telephone or email. If participants contacted the HIV Prevention Lab via telephone, they immediately completed a brief telephone interview to determine whether they met eligibility criteria for this study. Participants who contacted the HIV Prevention Lab via email were asked to provide a telephone number where they could be reached to complete the brief telephone interview and were contacted at their convenience. If eligible, participants were invited to the HIV Prevention Lab at Ryerson University for a one-hour session during which they completed a computer-assisted selfinterview (CASI) questionnaire package (see Appendix B). CASI reduces the amount of missing data compared to pen and paper interviewing (Hallfors, Khatapoush, Kadushin, Watson, \& Saxe, 2000; Johnson et al., 2001). In addition, individuals are more likely to report higher levels of alcohol use and illicit drug use in a CASI than on pen and paper interviewing (Wright, Aquilino, \& Supple, 1998). Therefore, participants may be more likely to report other sensitive or stigmatized behaviours, such erectile difficulties. All participants provided written informed consent at the outset of the study (see Appendix C). Three months and six months following their initial appointment, participants were contacted and scheduled for a subsequent one-hour session to complete the same CASI questionnaire package. Participants received $\$ 30$ and a list of community resources, including HIV testing and mental health or substance use counseling services (see Appendix D) at the end of each session attended.

\section{Measures}

Sociodemographic characteristics. Participants completed a demographic questionnaire where they indicated their age, gender identity, sexual orientation, relationship status, employment status, highest level of education, annual income, religion, and ethnic background. 
In addition, participants reported their self-identified anal sex role. Participants also stated their current HIV status and the last time they took an HIV test.

Internalized homophobia. To assess the extent to which participants held negative beliefs regarding their homosexual orientation, the Internalized Homophobia scale (IHP; Herek, Cogan, Gillis, \& Glunt, 1997) was administered. The IHP includes 9 statements (e.g., "I have tried to become more sexually attracted to women") and instructs participants to indicate on a 5point Likert scale (ranging from $1=$ strongly disagree to $5=$ strongly agree) to what extent they agree with each statement. Total scores range from 9 to 45 , where higher total scores indicate higher internalized homophobia. The IHP exhibited high internal consistency $(\alpha=.83$ for men; Herek et al., 1997). In our sample, the IHP also demonstrated high internal consistency, ranging from $\alpha=.88$ to .89 across time points.

Cognitive anxiety symptoms. The State-Trait Inventory for Cognitive and Somatic Anxiety (STICSA; Ree, French, MacLeod, \& Locke, 2008) consists of 21-items developed to assess cognitive and somatic anxiety symptoms. For the purpose of this study, only the trait cognitive anxiety subscale was examined, which includes 10-items (e.g., "I cannot concentrate without irrelevant thoughts intruding"). Participants were asked to rate on a 4-point Likert scale (ranging from $1=$ not at all to $4=$ very much so) how true, in general, each statement is for them. Total scores range from 10 to 40, where higher scores reflect greater cognitive anxiety symptoms. The cognitive anxiety subscale exhibited high internal consistency ( $\alpha=.87$; Gros, Antony, Simms, \& McCabe, 2007). The cognitive anxiety subscale of the STICSA also demonstrated high internal consistency in the present sample (range $\alpha=.88$ to .90 ).

Erectile functioning. The International Index of Erectile Function for Men Who Have Sex With Men (IIEF-MSM; Coyne et al., 2010) was used to assess erectile difficulties over the 
past four weeks. The IIEF-MSM is a 22-item self-report measure comprised of five domains: erectile function, intercourse satisfaction, orgasmic function, sexual desire, and overall satisfaction. The IIEF-MSM is an adaptation of the original IIEF, which is a well-validated measure that was validated on a sample that was presumably heterosexual men (Rosen et al., 1997). The IIEF-MSM was created to respond to criticisms that the original IIEF did not take into account insertive or receptive anal intercourse, and other sexual behaviours which are common among gay and bisexual men, for which erections would facilitate sexual activity (e.g., oral sex; Coyne et al., 2010).

For the purpose of this study, the erectile function domain was examined. The erectile function domain consists of 11-items assessing erection frequency (e.g., how often were you able to get an erection during sexual activity), erection firmness (e.g., when you had erections with sexual stimulation, how often were your erections hard enough for penetration), penetration ability (e.g., how often were you able to penetrate your partner(s)), and erection confidence (e.g., how do you rate your confidence that you could get and keep an erection). Erection maintenance frequency (e.g., how often were you able to maintain your erection after you had penetrated your partner) and ability (e.g., how difficult was it to maintain your erection to completion of intercourse) were assessed separately for receptive and insertive anal intercourse, and nonpenetrative sexual activity. Participants responded on a 6-point Likert scale (e.g., $0=$ never, $5=$ always/almost always) indicating increasing severity. Total cutoff scores of erectile dysfunction severity are based on the six items that performed the highest ( $r=.57$ to .68; Coyne et al., 2010). Total scores range from 0 to 30, where a score of 10 or less is indicative of severe erectile dysfunction, 11-15 of moderate erectile dysfunction, 16-24 of mild/moderate erectile dysfunction, and 25-30 of no erectile dysfunction (Coyne et al., 2010; Shindel et al., 2012). 
The IIEF-MSM erectile functioning domain demonstrated high internal consistency $(\alpha=$ .82; Coyne et al., 2010). When only considering the six items that performed the highest, the standardized Cronbach's alpha increased to 0.85 (Coyne et al., 2010). In the current sample, the erectile functioning domain exhibited high internal consistency (range $\alpha=.72$ to .76 ).

\section{Data analysis}

Prior to exploring the study hypotheses, Pearson correlations, independent t-tests, and one-way analyses of variance (ANOVAs) were conducted to determine whether specific demographic variables were associated with erectile functioning. Since older men more commonly report erectile difficulties (e.g., Bancroft et al., 2005; Laumann et al., 1999; Laumann et al., 2007; Shindel et al., 2012), age was examined as a covariate. Similarly, in a study comparing the prevalence of erectile difficulties among White, Hispanic, and Black Americans, Black Americans reported the highest prevalence of erectile difficulties (Laumann et al., 2007). The lack of a committed relationship is also a significant predictor of moderate to severe erectile dysfunction among gay men (e.g., Hirschfield et al., 2010; Shindel et al., 2012). Therefore, exploratory analyses were conducted to investigate whether there were differences in erectile function among the ethnic groups included in our sample and partnered versus non-partnered participants. Although simple associations between the model variables are not necessary for an indirect effect to exist (Hayes, 2009), the intercorrelations between study variables were also examined.

Traditionally, researchers examined mediation effects using Baron and Kenny’s (1986) causal steps approach, which involves testing each path in the model and then deducing whether a variable mediates the effect according to a specific set of statistical criteria. More recently, statisticians identified a number of criticisms of this method. First, the causal steps approach 
yields very low power to detect an indirect effect (Fritz \& MacKinnon, 2007). Second, due to the number of tests conducted in the causal steps approach, the results are vulnerable to Type I error (Hayes, 2009). Finally, researchers often use the Sobel test, which tests whether the product of the coefficients, $a b$, is statistically different from zero, to supplement the causal steps approach (Hayes, 2009). However, the Sobel test requires the sample distribution of $a b$ to be normal, which is often not the case (Hayes, 2009). In consideration of these limitations, an alternative method to examine indirect mediating effects, known as bootstrapping, was developed.

Bootstrapping is a non-parametric test that uses resampling to approximate the sampling distribution of the indirect effect (Hayes, 2009, 2013; Preacher \& Hayes, 2004). More specifically, bootstrapping involves 1) repeatedly resampling from the data to form a new sample based on the original data and 2) calculating the indirect effect, $a b$, for the resampled data set (Hayes, 2009, 2013; Preacher \& Hayes, 2004). This process is repeated between 1,000 and 50,000 times, creating an estimate of the sampling distribution of the indirect effect, $a b$, which is used to compose confidence intervals for the indirect effect (Hayes, 2009, 2013; Preacher \& Hayes, 2004).

Bootstrapping possesses many advantages. First, as is the case with most non-parametric tests (Fields, 2009), bootstrapping does not require the sample or the indirect effect to be normally distributed (Hayes, 2009, 2013). Second, bootstrapping yields the highest power and best Type 1 error control of the available methods for investigating indirect effects (Preacher \& Hayes, 2004), particularly among small to moderate sample sizes (Fritz \& MacKinnon, 2007). Finally, bootstrapping produces confidence intervals more accurately represent true rather than ideal sample distributions (Hayes, 2009). 
Considering these strengths, the cross-sectional and longitudinal associations between internalized homophobia and erectile function, indirectly influenced by cognitive anxiety symptoms, were estimated using a bootstrap method of inference (e.g., Hayes, 2013; Preacher \& Hayes, 2004). When examining the longitudinal association, baseline cognitive anxiety symptoms and erectile function were entered as covariates in order to assess change over time (Hayes, 2014). Bootstrapping mediation analyses were conducted to examine total, direct, and indirect effects using the PROCESS macro for SPSS (Hayes, 2013). PROCESS is statistical tool used to estimate direct and indirect effects in mediation models (Hayes, 2013). PROCESS generates $95 \%$ bias-corrected bootstrap confidence intervals for inference about indirect effects in mediation models (Hayes, 2013). Since these confidence intervals are established through the random resampling of the data, the endpoints vary with each analysis. In order to reduce sampling variation and achieve maximal statistical precision, Hayes (2013) recommends increasing the number of bootstrap samples to 10,000 . 
Table 2

Skewness and Kurtosis of the Study Variables

\begin{tabular}{|c|c|c|c|c|c|c|}
\hline \multirow[b]{2}{*}{ Variables } & \multicolumn{3}{|c|}{ Skewness } & \multicolumn{3}{|c|}{ Kurtosis } \\
\hline & Statistic & $S E$ & $z$ & Statistic & $S E$ & $z$ \\
\hline $\begin{array}{l}\text { Internalized } \\
\text { Homophobia (T1) } \\
\text { Cognitive } \\
\text { Anxiety }\end{array}$ & .99 & .15 & $6.60 * * *$ & .08 & .31 & 0.26 \\
\hline Symptoms (T1) & .53 & .15 & $3.53 * * *$ & -.41 & .31 & 1.32 \\
\hline $\begin{array}{l}\text { Erectile Function } \\
\text { (T1) } \\
\text { Cognitive }\end{array}$ & -.33 & .15 & $2.16^{*}$ & -.79 & .31 & $2.55^{*}$ \\
\hline $\begin{array}{l}\text { Anxiety } \\
\text { Symptoms (T2) } \\
\text { Erectile Function }\end{array}$ & .55 & .15 & $3.67 * * *$ & -.43 & .31 & 1.32 \\
\hline (T3) & -.39 & .15 & $2.60 * *$ & -.76 & .31 & $2.45^{*}$ \\
\hline
\end{tabular}

Note. $\mathrm{SE}=$ standard error; $\mathrm{T} 1=$ baseline; $\mathrm{T} 2=3$-month follow-up; $\mathrm{T} 3=6$-month follow-up.

$* \mathrm{p}<.05 . * * \mathrm{p}<.01 . * * * \mathrm{p}<.001$ 


\section{Results}

\section{Exploring assumptions}

In order to detect univariate outliers, box plots for each of the model variables (i.e., internalized homophobia, cognitive anxiety symptoms, erectile function) were examined. Any score with a $z$-value that exceeded $|3.29|$ was replaced with the next highest score plus one until no outliers remained (Field, 2009). Regarding baseline internalized homophobia, eight scores were changed. Three scores were altered for baseline cognitive anxiety symptoms and two scores were changed for 3-month cognitive anxiety symptoms. There were no outliers for baseline and 6-month erectile function. Transforming these outliers did not alter the simple associations and mediation analyses.

Although bootstrapping does not require the study variables to be normally distributed (Hayes, 2009, 2013), skewness, kurtosis, p-plots, and histograms were examined. Table 2 shows the skewness and kurtosis for each of the model variables. Positive values of skewness indicate that scores are clustered at the lower end whereas negative values of skewness denote that scores are clustered at the higher end (Field, 2009). According to $z$-scores and visual review of the histograms, the study variables were not normally distributed. Internalized homophobia and cognitive anxiety symptom scores tended to cluster on the lower end, while erectile function scores clustered toward the higher end.

\section{Descriptive Statistics}

Covariates. The associations between the model variables (i.e., internalized homophobia, cognitive anxiety symptoms, erectile functioning) and possible covariates (i.e., age, ethnicity, relationship status) were explored. Although age was not significantly correlated with internalized homophobia, $r(252)=-.01, p=.89$, and erectile functioning $r(250)=-.07, p=.30$ at 
baseline, age was significantly associated with cognitive anxiety symptoms, $r(252)=-.16, p<$ $.05, r^{2}=.025$, at baseline. In other words, greater age was associated with lower cognitive anxiety symptoms. Three separate ANOVAs were conducted to explore differences between ethnicity groups on the study variables. Ethnicity was significantly associated with erectile function, $F(6,249)=2.61, p<.05, \eta^{2}=.06$, and internalized homophobia, $F(6,251)=3.56, p<$ $.01, \eta^{2}=.08$. Tukey HSD post hoc tests revealed that South Asian men reported significantly worse erectile function $(M=16.20, S D=7.36)$ than Middle Eastern men $(M=26.67, S D=3.39)$, mean difference $=-10.47, S E=3.27, p<.05,95 \% \mathrm{CI}=[-20.19,-0.74]$, Cohen's $d=-1.83$. In addition, Black men reported significantly higher internalized homophobia $(M=20.75, S D=$ 9.72) compared to White men $(M=14.07, S D=6.40)$, mean difference $=6.68, S E=1.69, p<$ $.01,95 \% \mathrm{CI}=[1.64,11.72]$, and men who identified with more than one ethnicity $(M=14.52$, $S D=5.13)$, mean difference $=6.22, S E=1.84, p<.05,95 \% \mathrm{CI}=[0.76,11.70]$. There were no differences between ethnicity groups on cognitive anxiety symptoms, $F(6,251)=0.76, p=.60$. Regarding relationship status, t-tests revealed no differences between partnered and single participants on internalized homophobia $t(250)=0.69, p=.49$, and cognitive anxiety symptoms $t(250)=1.37, p=.17$. However, partnered participants reported significantly better erectile function $(M=21.94, S D=6.14)$ than single participants $(M=18.60, S D=7.06), t(248)=-3.82$, $p<.01$, Cohen's $d=0.50$. Therefore, ethnicity and relationship status were included as covariates in subsequent analyses. Although age was not significantly associated with erectile function in our sample, age was also included as a covariate since the literature consistently indicates that age is a predictor of erectile function (e.g., Laumann et al., 2007).

Erectile function. Table 3 presents the severity of erectile dysfunction among the study sample based on the criteria reported by Shindel et al. (2012). The percentage of participants 
Table 3

Severity of Erectile Dysfunction (using Shindel et al., 2012)

\begin{tabular}{|c|c|c|c|c|}
\hline & & Baseline & 3-month follow-up & 6-month follow-up \\
\hline Severity of ED & IIEF-MSM-EF Score & $n(\%)$ & $n(\%)$ & $n(\%)$ \\
\hline No ED & $25-30$ & $85(33.7)$ & $73(29.0)$ & $71(28.2)$ \\
\hline Mild & $16-24$ & $85(33.7)$ & $77(30.6)$ & $75(29.8)$ \\
\hline Moderate & $11-15$ & $48(19.0)$ & $51(20.2)$ & $44(17.5)$ \\
\hline Severe & $\leq 10$ & $32(12.7)$ & $51(20.2)$ & $62(24.6)$ \\
\hline
\end{tabular}

Note. ED = Erectile Dysfunction; IIEF-MSM-EF = International Index of Erectile Function for Men Who Have Sex With Men - Erectile Function subscale. Two participants did not fully complete the IIEF at baseline. Therefore, their data were not included. 
reporting moderate to severe erectile dysfunction increased across time from $31.7 \%$ at baseline, $40.4 \%$ at 3 -months, to $42.1 \%$ at 6 -months. In fact, the number of participants who reported experiencing severe erectile dysfunction doubled from baseline (12.7\%) to 6-month follow-up (24.6\%). There was a significant association between baseline and 3-month severity of erectile dysfunction, $\chi^{2}(9)=95.05, p<.01$, Cramer's $V=.36$, baseline and 6-month severity of erectile dysfunction, $\chi^{2}(9)=100.40, p<.01$, Cramer's $V=.37$, and 3-month and 6-month severity of erectile dysfunction, $\chi^{2}(9)=145.83, p<.01$, Cramer's $V=.44$.

\section{Simple associations}

Table 4 provides the intercorrelations for the study variables. As hypothesized, internalized homophobia was positively associated with cognitive anxiety symptoms whereas erectile function was negatively associated with both internalized homophobia and cognitive anxiety symptoms. More specifically, at baseline, internalized homophobia and cognitive anxiety symptoms were significantly correlated, $r(252)=.23, p<.01, r^{2}=.052$. At 3-month follow-up, internalized homophobia was significantly correlated with cognitive anxiety symptoms, $r(252)=$ $.22, p<.01, r^{2}=.048$, and erectile function, $r(250)=-.13, p<.05, r^{2}=.017$. Similarly, cognitive anxiety symptoms and erectile function were significantly correlated at 3-month follow-up, $r(252)=-.19, p<.01, r^{2}=.036$. Finally, at 6-month follow-up, internalized homophobia and cognitive anxiety symptoms were significantly correlated, $r(252)=.18, p<.01, r^{2}=.032$.

\section{Simple mediation model}

Cross-sectional analyses. Hypothesis 3 posits that internalized homophobia affects erectile functioning indirectly through cognitive anxiety symptoms. To examine this model, a simple mediation analysis was conducted using ordinary least squares path analysis in PROCESS. As illustrated in Table 5 and Figure 3, internalized homophobia significantly 
Table 4

Correlations between Internalized Homophobia, Cognitive Anxiety Symptoms, and Erectile Function

\begin{tabular}{|c|c|c|c|c|c|c|c|c|c|}
\hline & 1 & 2 & 3 & 4 & 5 & 6 & 7 & 8 & 9 \\
\hline $\begin{array}{l}\text { 1. Internalized } \\
\text { Homophobia (T1) }\end{array}$ & - & & & & & & & & \\
\hline $\begin{array}{l}\text { 2. Cognitive Anxiety } \\
\text { Symptoms (T1) }\end{array}$ & $.23^{* *}$ & - & & & & & & & \\
\hline $\begin{array}{l}\text { 3. Erectile Functioning } \\
\text { (T1) }\end{array}$ & -.11 & -.07 & - & & & & & & \\
\hline $\begin{array}{l}\text { 4. Internalized } \\
\text { Homophobia (T2) }\end{array}$ & $.86^{* *}$ & $.19^{* *}$ & $-.14^{*}$ & - & & & & & \\
\hline $\begin{array}{l}\text { 5. Cognitive Anxiety } \\
\text { Symptoms (T2) }\end{array}$ & $.19^{* *}$ & $.71^{* *}$ & $-.18^{* *}$ & $.22^{* *}$ & - & & & & \\
\hline $\begin{array}{l}\text { 6. Erectile Functioning } \\
\text { (T2) }\end{array}$ & -.11 & -.12 & $.57^{* *}$ & $-.13^{*}$ & $-.19^{* *}$ & - & & & \\
\hline $\begin{array}{l}\text { 7. Internalized } \\
\text { Homophobia (T3) }\end{array}$ & $.83^{* *}$ & $.12^{*}$ & -.08 & $.85^{* *}$ & $.14^{*}$ & -.07 & - & & \\
\hline $\begin{array}{l}\text { 8. Cognitive Anxiety } \\
\text { Symptoms (T3) }\end{array}$ & $.26^{* *}$ & $.72^{* *}$ & -.12 & $.26^{* *}$ & $.77^{* *}$ & $-.15^{*}$ & $.18^{* *}$ & - & \\
\hline $\begin{array}{l}\text { 9. Erectile Functioning } \\
\text { (T3) }\end{array}$ & -.07 & -.07 & $.55^{* *}$ & -.09 & -.11 & $.62^{* *}$ & -.08 & -.11 & - \\
\hline
\end{tabular}

Note. $\mathrm{T} 1=$ baseline; $\mathrm{T} 2=3$-month follow-up; $\mathrm{T} 3=6$-month follow-up

$* \mathrm{p}<.05 . * * \mathrm{p}<.01$ 
Table 5

Unstandardized Path Coefficients for the Cross-sectional Mediation Model

\begin{tabular}{|c|c|c|c|c|c|c|c|c|}
\hline \multirow[b]{3}{*}{ Predictors } & & \multicolumn{7}{|c|}{ Outcome variables } \\
\hline & & \multicolumn{3}{|c|}{$\begin{array}{c}\text { Cognitive anxiety } \\
\text { symptoms }\end{array}$} & & \multicolumn{3}{|c|}{ Erectile function } \\
\hline & & Coeff. & $S E$ & $p$ & & Coeff. & $S E$ & $p$ \\
\hline $\mathrm{IH}$ & $a$ & .22 & .06 & $<.001$ & $c^{\prime}$ & -.10 & .07 & .14 \\
\hline CA & & - & - & - & $b$ & -.05 & .07 & .50 \\
\hline \multirow[t]{2}{*}{ Constant } & & 21.90 & 2.01 & $<.001$ & & 19.41 & 2.70 & $<.001$ \\
\hline & & \multicolumn{3}{|c|}{$\mathrm{R}^{2}=.09$} & & \multicolumn{2}{|c|}{$\mathrm{R}^{2}=.07$} & $<.001$ \\
\hline
\end{tabular}

Note . IH = Internalized Homophobia; $\mathrm{CA}=$ Cognitive Anxiety Symptoms; $\mathrm{SE}=$ standard error .

${ }^{\mathrm{a}}$ Control variables included age, ethnicity, and relationship status. 


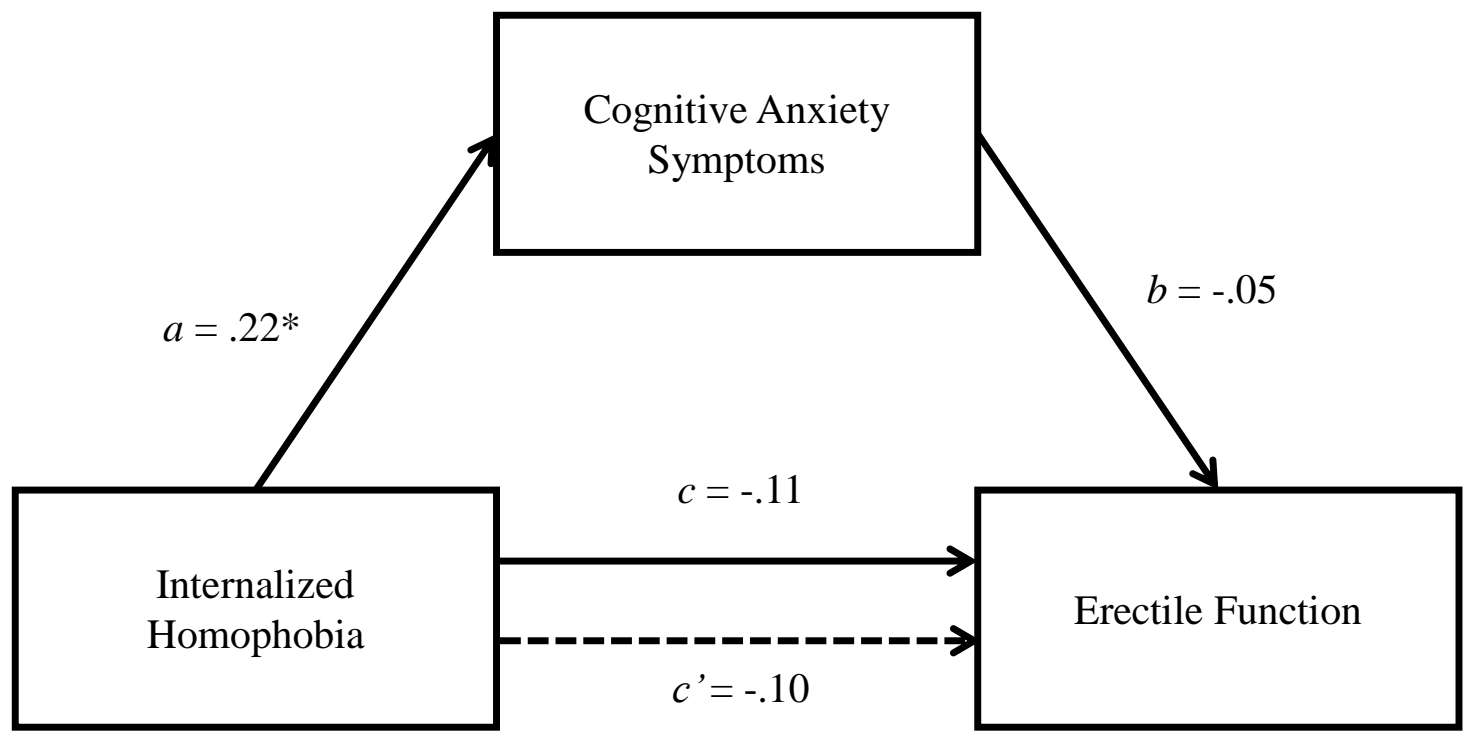

Figure 3. Path coefficients for cross-sectional mediation model. Unstandardized OLS regression coefficients are reported. The $c$ ' path depicts the effect of internalized homophobia on erectile function when cognitive anxiety is not included as a mediator (i.e., direct effect). ${ }^{a}$ Control variables included age, ethnicity, and relationship status.

$* p<.001$ 
predicted cognitive anxiety symptoms $(a=.22, p<.001)$, where higher internalized homophobia was associated with greater cognitive anxiety symptoms. However, cognitive anxiety symptoms did not predict erectile function $(b=-.05, p=.50)$. Internalized homophobia did not indirectly influence erectile function through its effect on cognitive anxiety symptoms. A bias-corrected bootstrap confidence interval for the indirect effect $(a b=-.01)$ based on 10,000 bootstrap samples crossed zero (-.05 to .02$)$, indicating that it is not possible to reject the null hypothesis. In addition, internalized homophobia did not influence erectile function independent of its effects on cognitive anxiety symptoms $\left(c^{\prime}=-.10, p=.14\right)$.

Longitudinal analyses. Hypothesis 4 proposes that baseline internalized homophobia indirectly reduces erectile functioning at 6-month follow-up through increases in cognitive anxiety symptoms at 3-month follow-up. To examine this model, a simple mediation analysis was conducted using ordinary least squares path analysis in PROCESS. In order to assess change over time, baseline measures of cognitive anxiety symptoms and erectile function were entered as covariates. As depicted in Table 6 and Figure 4, baseline internalized homophobia did not significantly predict cognitive anxiety symptoms at 3 -months $(a=.030, p=.50)$ and cognitive anxiety symptoms at 3-months did not significantly predict erectile function at 6 -months $(b=$ $.008, p=.94)$. In addition, internalized homophobia did not indirectly influence erectile function at 6-months through its effect on cognitive anxiety symptoms at 3-months. A bias-corrected bootstrap confidence interval for the indirect effect $(a b=.0002)$ based on 10,000 bootstrap samples crossed zero (-.010 to .008). Furthermore, internalized homophobia did not influence erectile function at 6-months independent of its effects on cognitive anxiety symptoms at 3months $\left(c^{\prime}=-.004, p=.95\right)$. 
Table 6

Unstandardized Path Coefficients for the Longitudinal Mediation Model

\begin{tabular}{|c|c|c|c|c|c|c|c|c|}
\hline \multirow[b]{3}{*}{ Predictors } & & \multicolumn{7}{|c|}{ Outcome variables } \\
\hline & & \multicolumn{3}{|c|}{$\begin{array}{l}\text { 3-month cognitive anxiety } \\
\text { symptoms }\end{array}$} & & \multicolumn{3}{|c|}{ 6-month erectile function } \\
\hline & & Coeff. & $S E$ & $p$ & & Coeff. & $S E$ & $p$ \\
\hline & $a$ & .030 & .045 & .50 & $c^{\prime}$ & -.004 & .069 & .95 \\
\hline 3-mth CA & & - & - & - & $b$ & .008 & .098 & .94 \\
\hline \multirow[t]{2}{*}{ Constant } & & 5.66 & 2.02 & $<.01$ & & 3.60 & 3.13 & .25 \\
\hline & & \multicolumn{3}{|c|}{$\mathrm{R}^{2}=.52$} & & \multicolumn{3}{|c|}{$\mathrm{R}^{2}=.31$} \\
\hline
\end{tabular}

Note. $\mathrm{IH}=$ Internalized Homophobia; $\mathrm{CA}=$ Cognitive Anxiety Symptoms; $\mathrm{SE}=$ standard error. ${ }^{\mathrm{a}}$ Control variables included age, ethnicity, relationship status, baseline cognitive anxiety symptoms, and baseline erectile function. 


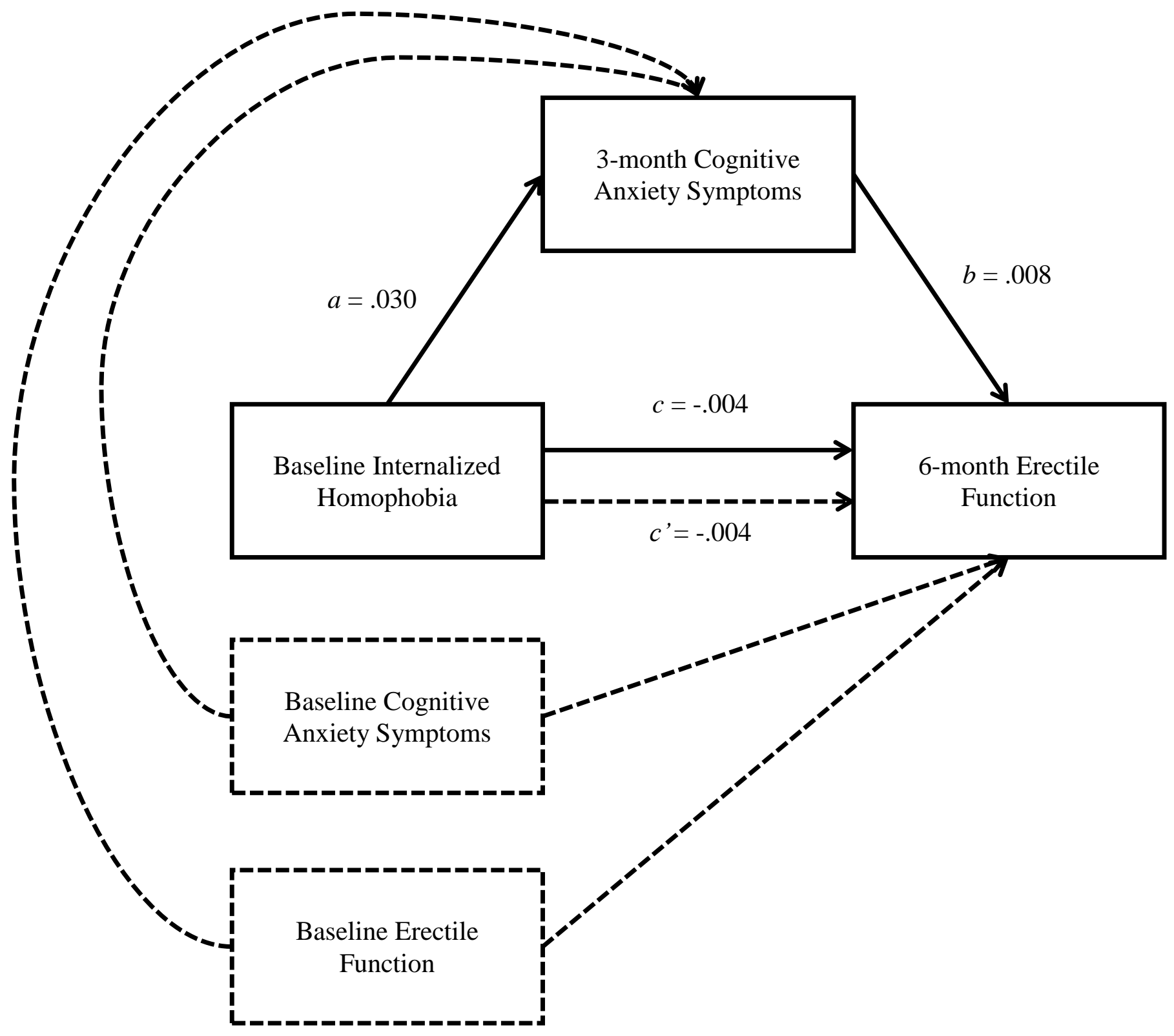

Figure 4. Path coefficients for longitudinal mediation model. Unstandardized OLS regression coefficients are reported. The $c$ ' path depicts the effect of baseline internalized homophobia on 6-month erectile function when 3-month cognitive anxiety is not included as a mediator (i.e., direct effect).

${ }^{a}$ Control variables included age, ethnicity, relationship status, baseline cognitive anxiety symptoms, and baseline erectile function. 


\section{Discussion}

This study proposed and tested a psychosocial model of erectile dysfunction for gay men. More specifically, this study examined the relationship between internalized homophobia, cognitive anxiety symptoms, and erectile function across three time points (i.e., baseline, 3months, and 6-months). It was hypothesized that, at all three time points, higher internalized homophobia would be associated with higher cognitive anxiety symptoms whereas lower erectile function would be associated with both higher internalized homophobia and higher cognitive anxiety symptoms. Based on the proposed model, cognitive anxiety symptoms were expected to account for the relationship between internalized homophobia and erectile function at baseline. It was further hypothesized that cognitive anxiety symptoms at 3-months would account for the relationship between baseline internalized homophobia and erectile function at 6-months.

\section{Summary of Findings}

Age: Contrary to previous study findings, greater age was not associated with lower erectile function. Although the age of the study participants ranged from 18 to 81 years, the mean age of the study sample was younger than 40 years old. Increases in erectile dysfunction, however, are most likely to develop after the age of 40 years (e.g., Hirschfield et al., 2010; Laumann et al., 1999; Laumann et al., 2007; McKinlay, 2000). Therefore, the lack of association between age and erectile function may be due to the present sample's young age.

Relationship status: Consistent with the current literature, partnered participants reported better erectile function than single participants. Researchers suggest that single MSM may be more likely to experience erectile difficulties due to lack of experience and/or increased anxiety during casual sexual encounters (e.g., Hirschfield et al., 2010). In a study assessing gay men's self-defined sexual problems in casual sexual encounters, commonly reported difficulties 
included negative or inhibiting psychological state before, during, or following the encounter, discrepancies between partners regarding desired sexual behaviour, fear of contracting an STI, and fear of discrimination (Cove \& Boyle, 2002). These factors may negatively affect erectile function and account for the differences in erectile function found between partnered and single participants in this sample.

Ethnicity: Regarding differences in erectile function between ethnic groups, South Asian men rated their erectile function as worse than Middle Eastern men. No differences in erectile function were found between other ethnic groups. Although variation in erectile function across ethnic groups may be due to genetic factors, systemic and cultural issues may also play a role. For instance, researchers show that ethnic groups differ in their attitudes toward erectile dysfunction (e.g., Perelman, Shabsigh, Seftel, Althof, \& Lockhart, 2005), health seeking behaviours (e.g., Millett et al., 2012), as well as access to health care (e.g., Wilson \& Yoshikawa, 2007). In this instance, however, the difference in erectile function between South Asian and Middle Eastern men may be an artifact of the IIEF-MSM erectile function subscale.

The IIEF-MSM erectile function subscale does not adequately account for gay men's preferred role during anal intercourse. Gay men who prefer being insertive (i.e., penetrating their partner) during anal intercourse self-identify as "top," whereas gay men who prefer being receptive (i.e., penetrated by their partner) during anal intercourse identify as "bottoms" (e.g., Moskowitz, Rieger, \& Roloff, 2008; Weinrich, Grant, Jacobson, Robinson, \& McCutchan, 1992). The label "versatile" describes gay men who equally prefer either insertive or receptive roles (e.g., Moskowitz et al., 2008; Weinrich et al., 1992). The IIEF-MSM erectile function subscale total score includes two insertive anal intercourse items, one receptive anal intercourse item, one item regarding erectile function during non-intercourse sexual activity, and two items 
assessing erectile function overall. Consequently, men who identify as "versatile" receive the best erectile function scores since all items are relevant to their sexual experiences, whereas men who identify as "bottoms" receive the worst erectile function scores because only four of the six items are relevant to their sexual behaviour.

Among the Middle Eastern men in the sample, two identified as exclusively "top" $(33.3 \%)$ and four identified as "versatile" with a preference for the insertive role $(66.6 \%)$. In contrast, five South Asian men identified as exclusively "top" (33.3\%) and one man identified as exclusively "bottom" (6.7\%). Of the seven South Asian men who identified as "versatile" (46.6\%), two men endorsed a preference for the insertive role and two men endorsed a preference for the receptive role. In addition, two South Asian men reported that they do not engage in anal intercourse (13.3\%), and therefore, do not have a preferred anal sex role. The difference in erectile function between South Asian and Middle Eastern men is likely due to the higher proportion of self-identified "bottoms" and men who do not engage in anal intercourse among the South Asian men compared to the Middle Eastern men in this sample. Future research would benefit from further investigating how ethnicity and culture influence erectile function, while simultaneously accounting for differences in preferred anal sex roles.

Severity of erectile dysfunction: The prevalence of moderate to severe erectile dysfunction in the sample ranged from $31.7 \%$ to $42.1 \%$ across the six month time period. However, the increase in the prevalence of moderate to severe erectile dysfunction across the six month period is, once again, likely an artifact of the of the IIEF-MSM erectile function subscale. When a participant indicates that they have had "no sexual activity" in the past month, their IIEF-MSM erectile function subscale score is lower and interpreted as poor erectile function (Coyne et al., 2010). At baseline, one man reported no sexual activity in the past month 
compared to five men at 3-month follow-up and ten men at 6-month follow-up. The increase in the number of participants reporting "no sexual activity" likely accounts for the rise in the prevalence of moderate and severe erectile dysfunction from baseline to 6-month follow-up.

Although it is difficult to determine whether these findings are consistent with the current literature due to the varied methodology used to assess erectile function across studies, the literature suggests that the prevalence reported in this thesis may be elevated. In one study of gay men's sexual functioning, 3.6\% of men reported experiencing erectile difficulties most of the time and $6.5 \%$ reported experiencing erectile difficulties less than half the time over the past three months, which is a significantly lower rate than reported in the present sample (Bancroft et al., 2005). This discrepancy may be due to demographic differences between the samples. For instance, the sample included in Bancroft and colleagues' (2005) study was younger $(M=34.8$, $S D=10.5)$ than the present study sample $(M=37.88, S D=12.97), t(1446)=4.05, p<.01$. Alternatively, these differences may be an artifact of using the IIEF-MSM to assess erectile dysfunction rather than a single question (i.e., "In the past three months, have your experienced any difficulty in obtaining or maintaining a full erection during sexual activity?’) posed by Bancroft and colleagues (2005). In an Internet sample of American MSM, 45\% of men reported experiencing erectile difficulties in past 12 months (Hirschfield et al., 2010). However, in contrast to the present study, which administered the IIEF-MSM, the authors used a single item (i.e., "In the past 12 months, was there a period of time where you had trouble achieving or maintaining an erection?") and did not assess the severity of erectile function. Additional studies investigating the prevalence and severity of erectile dysfunction among gay men are needed.

Simple associations: The study hypotheses regarding the simple associations between internalized homophobia, cognitive anxiety symptoms, and erectile function were partially 
supported. As predicted, higher internalized homophobia was associated with higher cognitive anxiety symptoms at baseline, 3-months, and 6-months. Higher internalized homophobia was only associated lower erectile function at 3-months. Although the association between internalized homophobia and erectile function was not significant at baseline and 6-months, the direction of the relationship was as expected at both time points. These findings are consistent with the literature examining the adverse effects of minority stress on gay men's mental and sexual health (e.g., Hatzenbuehler et al., 2008). Furthermore, higher cognitive anxiety symptoms were associated with lower erectile function at 3-months, supporting theories of sexual arousal that postulate that cognitive anxiety symptoms negatively affect erectile function (e.g., Barlow, 1986). The present study expanded upon previous research investigating the effects of minority stress and cognitive anxiety by examining the relationship between internalized homophobia, cognitive anxiety symptoms, and erectile function over a 6-month period rather than at one time point.

Simple Mediation Models: Based on theories of minority stress and sexual arousal, cognitive anxiety symptoms were hypothesized to explain the inverse relationship between internalized homophobia and erectile function among gay men at baseline and across 6-months. However, neither the cross-sectional nor the longitudinal hypotheses were supported. Although higher internalized homophobia predicted higher cognitive anxiety symptoms at baseline, higher cognitive anxiety symptoms did not predict lower erectile function. In addition, internalized homophobia was not associated with erectile function indirectly via cognitive anxiety symptoms at baseline or across 6-months. 


\section{Limitations}

There are a number of possible reasons that the proposed model was not supported. First, researchers found that cognitive anxiety reduced the physiological sexual arousal (i.e., erection) of men with poor sexual functioning, exclusively (e.g., Abrahamson et al., 1985; Beck et al., 1983). Since the present study included only one measure of sexual functioning, which served as the outcome variable (i.e., IIEF-MSM), participants could not be divided into groups of men with good versus poor sexual functioning. Consequently, the proposed model may not have been supported due to the exclusion of this potential moderator. Future research would benefit from recruiting men with poor and good sexual functioning, as per the criteria outlined in the Diagnostic and Statistical Manual of Mental Disorders, Fifth Edition (DSM-5; APA, 2013), in order to investigate differences between these groups of men.

Second, the trait cognitive anxiety subscale of the STICSA does not assess cognitive anxiety symptoms experienced specifically during sexual activity. Researchers stress the importance of distinguishing between trait and state anxiety due to differences in their conceptualization and associated correlates (e.g., Endler \& Kocovski, 2001). Trait anxiety, for instance, is a stable predisposition to perceive threat, whereas state anxiety is a transient response to a specific situation (e.g., Endler \& Kocovski, 2001). Since the aims of this study related to cognitive anxiety experienced during sexual situations, a state cognitive anxiety measure would likely be an appropriate assessment tool that may have supported the proposed model. For instance, Nobre and Pinto-Gouveia (2003) developed a self-report questionnaire that assesses negative automatic thoughts, emotions, and sexual arousal during sexual activity, which would be an appropriate measure to administer in future research. 
Third, the study sample, on average, reported low internalized homophobia across the three assessment points of the 6-month time period $(M=15.04-15.29, S D=6.37-6.62)$. In other words, on average, participants mostly answered, "strongly disagree" or "disagree" to the questionnaire items (e.g., "I wish I weren't gay"). On the one hand, gay and bisexual men who are generally open and comfortable with their sexuality may be overrepresented in the present sample. This thesis is part of a larger study that recruited gay and bisexual men to participate "Gay Strengths Study" using advertisements reading, "Come tell us what you do to keep yourself sexually and mentally healthy." Future researchers would benefit from recruiting MSM, who do not identify as gay or bisexual, since individuals who do not identify with a gay identity, but engage in same-sex sexual behaviour, may report higher internalized homophobia. At the same time, in another study, gay men also reported low internalized homophobia on average $(M=$ 14.79; Herek et al., 1997). The Internalized Homophobia scale, therefore, may not be a sensitive measure, and only capture extreme cases. In order to account for the skewed distribution, Herek and colleagues (2007) divided the sample at the median in order to create two groups of gay men with high versus low internalized homophobia. Future researchers would benefit from examining whether internalized homophobia moderates the relationship between cognitive anxiety symptoms and erectile function.

\section{Future directions}

Methodology: Future researchers could incorporate several methodological amendments in order to improve the research design used to assess the current model. Although this study proposed and tested a model of psychogenic erectile dysfunction, the etiology of participants' erectile difficulties (i.e., psychological or organic factors) were not adequately assessed. For instance, participants were not asked to report comorbid medical conditions despite the fact that 
several medical conditions may result in erectile dysfunction, including but not limited to, diabetes (e.g., Dunn, Croft, \& Hackett, 1999; Levy, 2004), hypertension (e.g., Dunn et al., 1999; Levy, 1994), and HIV (Ende et al., 2006). Although participants self-reported their HIV serostatus, participants may not have completed an HIV test or may have chosen not to disclose their HIV-positive serostatus due to existing stigma and fear of exclusion from participating in the study. In addition, participants were not asked to list current medications. Yet, many medications, such as selective serotonin reuptake inhibitors (SSRIs; Hart et al., 2012), negatively affect erectile function. Furthermore, psychogenic and organic erectile dysfunction possess different developmental and maintaining mechanisms (e.g., Rosen, 2001). When investigating possible mechanisms of psychogenic erectile dysfunction, future researchers would benefit from assessing current and past medical conditions as well as medications that may impact sexual functioning.

In addition, this study administered the IIEF-MSM erectile function subscale, which possesses numerous limitations. As previously mentioned, the IIEF-MSM erectile function subscale interprets "no sexual activity" in the past month as poor erectile function (Coyne et al., 2010). The IIEF-MSM erectile function subscale, however, does take into account the reason for the participant's lack of sexual activity, which is major limitation of the measure and may inflate the percentage of individuals reporting erectile dysfunction. For example, an individual may not engage in sexual activity for a variety of reasons beyond erectile dysfunction including other sexual dysfunction, lack of an available partner(s), or lack of interest in certain sexual behaviours (e.g., anal intercourse). As was discussed earlier, the IIEF-MSM erectile function subscale also does not adequately account for gay men's preferred role during anal intercourse. In fact, the erectile function total score favours "versatiles" and disadvantages "bottoms." In the present 
sample, approximately $14 \%$ of individuals identified as exclusively bottom. Therefore, the imbalance of the IIEF-MSM may also have inflated the percentage of individuals reporting erectile dysfunction. Once again, it is difficult to compare whether the percentage of "bottoms" is higher among the current study compared to previous studies, since neither Hirschfield and colleagues (2010) nor Bancroft and colleagues (2005) reported the samples' self-identified anal sex roles. On the other hand, the IIEF-MSM instructions do not ask participants to respond to the listed questions based on sexual encounters where they did not use erectile enhancing medications, which may minimize participants' erectile difficulties.

In men, there is a strong correspondence between self-reported sexual arousal and physiological measures of erectile function (Chivers, Seto, Lalumiere, Laan, \& Grimbos, 2010; Sakheim, Barlow, Beck, \& Abrahamson, 1985). In order to account for the existing limitations of the IIEF-MSM, future researchers would benefit from incorporating a physiological measure of erectile function (e.g., penile strain gauge, thermal imaging). The inclusion of a physiological measure of erectile function would also corroborate self-reported erectile difficulties. Since cognitive anxiety symptoms and erectile function were not measured during sexual activity, and instead were assessed retrospectively, participants' responses may have been subject to recall bias. Future researchers would benefit from designing an experimental manipulation in order to infer causation and replicate the findings of the aforementioned experimental studies (e.g., Abrahamson et al., 1985; Beck et al., 1983) with gay and bisexual men.

Additional Models: Future researchers may also benefit from adapting and testing other models of psychogenic erectile dysfunction among gay men. For instance, Bancroft and Janssen (2000) proposed a dual control model of male sexual response based on evidence of excitatory and inhibitory mechanisms in the brain. The authors assert that individuals differ in their 
tendency for inhibition of sexual response and sexual excitation (Bancroft \& Janssen, 2000). Sexual inhibition consists of two components. The first factor (i.e., SIS1) relates to intrinsic fears of performance failure, possibly learned due to past erectile difficulties, which inhibit sexual arousal (Bancroft \& Janssen, 2000). In contrast, the second factor (i.e., SIS2) pertains to external threats in a sexual situation that inhibit sexual arousal, such as fears of being discovered, fear of a hostile response from a partner, or concerns regarding contracting an STI (Bancroft \& Janssen, 2000). Sexual excitation consists of one factor relating to an individual's propensity for arousability during sexual situations (Bancroft \& Janssen, 2000). Considering minority stress theory and the dual control model, it is possible that gay men with high internalized homophobia may initially exhibit higher SIS2 than gay men with low internalized homophobia, since these men tend to be hypervigilant to possible external threats (e.g., Meyer, 2003). Subsequently, their erectile difficulties may be maintained by internal processes (i.e., increases in SIS1) due to past learning that their erectile function is inconsistent. Investigating other models of psychogenic erectile dysfunction with gay men would answer such questions and improve the field's understanding of gay men's sexual health.

Moderators: This study also illuminated multiple possible moderators to be explored in future research regarding erectile function among gay and bisexual men. To date, no study has investigated whether differences in sexual functioning exist between self-identified preferred anal sex roles (i.e., top, bottom, versatile). Due to the limitations of the IIEF-MEM erectile function subscale, differences between self-identified anal sex roles could not be examined in the present study. However, MSM who identified as "top" reported higher internalized homophobia than MSM who identified as "versatile" (Hart et al., 2003). Therefore, future researchers should incorporate an individual's preferred anal sex role when testing the proposed model. 
Furthermore, the present study found differences in erectile function between ethnic groups. Future researchers should investigate whether differences in erectile function exist due to cultural, systemic, and/or genetic factors. Exploring these possible moderators will improve the current model, further the field's understanding of gay men's sexual health, and stimulate the development of research instruments that adequately assess gay men's sexual functioning.

\section{Implications}

Although the hypothesized model was not supported, there are nevertheless important implications from the current study on the understanding of erectile function among gay and bisexual men. Differences in erectile function between partnered versus non-partnered men and ethnic groups show that gay men share some similar non-biological risk factors for erectile dysfunction as heterosexual men. At the same time, higher internalized homophobia was associated with higher cognitive anxiety symptoms and lower erectile function, which highlights the importance of considering gay specific risk factors for erectile dysfunction. Treatment interventions designed to target minority stress may, therefore, effectively improve erectile function in gay and bisexual men. Pachankis (in press) developed an evidence-based cognitive and behavioural intervention, entitled ESTEEM, to help gay and bisexual men cope with minority stress and in turn reduce depression and anxiety symptoms. The six principles and exercises employed by the ESTEEM protocol to address the impact minority stress include 1) normalizing the negative mental consequence of minority stress, 2) restructuring negative cognitions resulting from experiences of minority stress, 3) empowering gay men to openly and assertively communicate across domains, 4) highlighting and validating gay men's unique strengths, 5) affirming healthy sexual experiences, and 6) facilitating supportive relationships. 
Future researchers should examine whether this intervention also reduces erectile dysfunction among gay men.

\section{Conclusion}

Guided by theories of minority stress and sexual arousal, this study proposed and examined a psychosocial model of erectile dysfunction for gay and bisexual men. Although the hypothesized model was not supported with neither cross-sectional nor longitudinal data, the study findings support theories of minority stress and sexual arousal as well as highlight the importance of considering psychosocial risk factors that are specific to gay men. Future researchers should continue to investigate the proposed model incorporating the outlined methodological suggestions outlined. Identifying the mechanisms involved in the development and maintenance of erectile dysfunction among gay men is important for the implementation of effective treatment strategies and gaining a more complete understanding of gay men's sexual health. 
Appendix A

Recruitment Materials

\section{Protective Factors Against HIV Risk Behaviour Among Gay and Bisexual Men: A Longitudinal Study}

Date:

Staff's name:

Where did you hear about our study?

Do you have a few minutes so that I can provide you with some additional information concerning our study?

\section{If yes:}

The goal of our study is to identify the protective factors and sexual strategies used by gay and bisexual men to keep themselves sexually healthy. The study will also examine how these protective factors and safer sex practices relate to one another in predicting low sexual risk behaviour.

As a participant, you would be required to attend three 1-hour sessions, during which you would complete a questionnaire package. The first session would be scheduled at your earliest convenience. Three-months and 6-months following your initial appointment, you would return for the second and third sessions, where you will once again complete a questionnaire package. For your participation, you will be compensated $\$ 30$ at each session you attend (for a total of \$90). A smaller group will be invited back to complete a qualitative interview where you would receive an additional $\$ 30$.

All study sessions will be conducted at our offices at Ryerson University, which is located downtown, near Dundas Square. I can give you more detailed directions at the end of our call today. We would like to emphasize that all participant information will be kept confidential. Any information you complete will be entered into our databases via a subject identification number; therefore, no names or contact information will be listed.

Do you have any questions at this point?

Would you be interested in participating in our study?

If yes:

So, now I am going to be asking you some questions to determine whether you are eligible to participate in our study.

1) How old are you? (Must be 18 years or older; refer to Ineligibility section, \#1) 
2) What is your HIV status? (Must be HIV-neg; refer to Ineligibility section, \#2)

3) When was the last time you engaged in any type of genital play with another male? (Must have engaged in sexual activity with another male within the last SIX months; refer to Ineligibility section, \#3)

4) Have you ever been diagnosed with a psychological problem? YES NO If yes, what was your diagnosis? Are you currently receiving treatment for this problem? YES NO If no, when did you stop treatment? Are you currently experiencing symptoms? YES NO (If participant is currently experiencing symptoms, refer to Ineligibility section, \#4)

\section{If a participant is eligible:}

5) What is your availability?

6) Where can we reach you in order to confirm your appointment?

NOTE: If the participant would like to leave a pseudonym, please ask them to make note of the name that they have provided.

Name:

Telephone number: Can we leave a message? YES $\mathrm{NO}$

Email address:

Your appointment is scheduled for:

Our office is located at 105 Bond Street, close to Yonge and Dundas. The closest subway station is Dundas station. We are located on the second floor, room 207. I will send you a confirmation email with this information.

\section{If a participant is ineligible:}

Thank you for your interest in our study. Unfortunately, you are not eligible to participate in this study at this time because

Possible reasons for ineligibility:

1) Age $\rightarrow$ We are seeking participants over the age of 18 .

2) $\mathrm{HIV}+\rightarrow$ Explain that this particular study is recruiting HIV-negative men. However, we are currently recruiting for the Gay Poz Sex study, which is a sexual health and research program for gay men who are HIV-positive. We would be happy to send you more information regarding the study. You may also contact Rick or Scott at 416-340-8484, ext. 277. If you are interested, do we have permission to give Rick you contact information? 
3) No sexual activity with another male in the last SIX months $\rightarrow$ Explain that we are seeking sexually active participants for this study. Ask the participant permission to recontact them in 3 months to reassess their eligibility.

4) Diagnosis \& currently experiencing symptoms for severe major depression, bipolar disorder, schizophrenia, or other severe mental illness that would hinder their ability to accurately complete the study. The participant is only ineligible if they are still experiencing symptoms. If you are unsure whether to exclude the participant, please consult with the lab manager. $\rightarrow$ Explain to the participant that we are seeking participants who are currently not experiencing symptoms or taking certain medications.

For referrals to specific therapists who work with specific problems (e.g. drug/alcohol abuse, social anxiety, etc.)

- Ontario Psychological Association

730 Yonge Street, Suite 221

Toronto, Ontario

Telephone: (416) 961-0069

Email: info@psych.on.ca

For Cognitive-behavioral therapy services for anxiety

- The Clinic on Dupont

(416) 515-2649

101 Dupont Street, Toronto, Ontario

- CAMH Anxiety Disorders Clinic 416-535-8501 ext. 6819

$11^{\text {th }}$ floor, 250 College street (at Spadina)

- Association of Cognitive and Behavioural Therapies www.abct.org

For general mental health and distress services:

- Centre for Addiction and Mental Health (CAMH)

(416) 979-6885

250 College Street, Toronto, Ontario

24-hours, 7 days per week emergency psychiatric assessment, treatment \& crisis follow-up

- Community Mental Health Crisis Response Program

(serves North York and Etobicoke area)

2 Lansing Square, Ste. 600

Toronto ON M2J 4P8

Phone: (416) 498-0043 
- Gerstein Centre (Crisis Line)

100 Charles Street East

Toronto, Ontario

(416) 929-5200

The Gerstein Centre provides crisis intervention to adults, living in the City of Toronto, who experience mental health problems. The Centre provides supportive counselling for immediate, crisis issues and referrals to other services for on-going, non-crisis issues.

- Distress Centres of Toronto 24-Hour Crisis Support Line (416) 408-4357

\section{Addiction treatment services:}

- CAMH Addiction Concerns (416) 595-6111 or 1-800-463-6273 (toll free).

- Bellwood Health Services 1-800-387-6198.

- Alcoholics Anonymous (416)487-5591

\section{For LGBT or HIV-related concerns:}

- ACT Services for People Living with HIV 399 Church St $-4^{\text {th }}$ Floor Toronto, Ontario (416) 340-2437

- David Kelley Services Lesbian, Gay \& HIV/AIDS Counseling 355 Church Street Toronto, Ontario (416) 595-9618 e-mail: dks@fsatoronto.com 


\section{The GAY STRENGTHS Study}

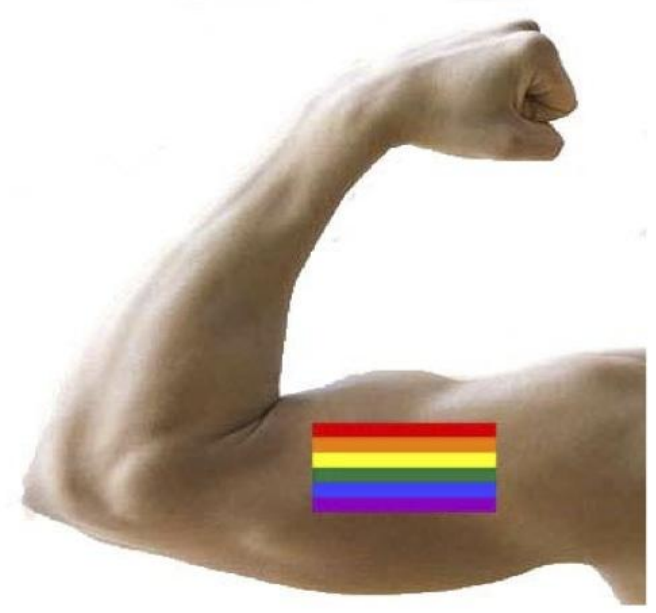

Despite challenges, gay \& bisexual men are strong and find ways to bounce back!

\section{Come tell us: \\ What you do to keep yourself sexually healthy}

Complete 3 surveys over 3 sessions

Receive $\$ 90$ for your participation!

To find out more about our study, please contact our research team at 416-979-5000, ext. 2179 or email gayNstrong@gmail.com.

ff facebook.com/gaynstrong

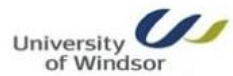

离 UNIIERSITY OF

RYERSON
UNIVERSITY

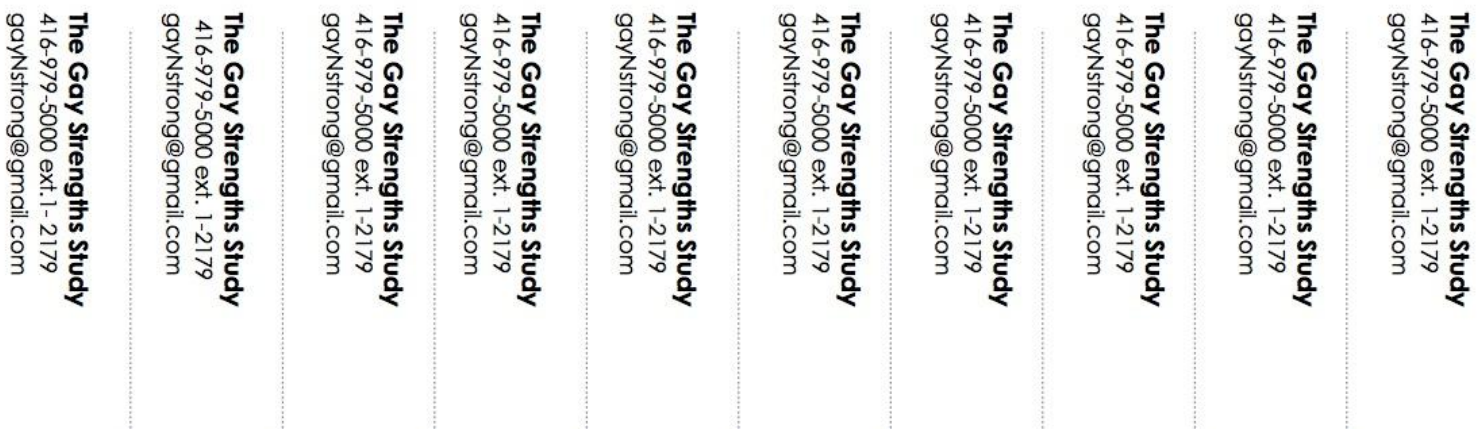




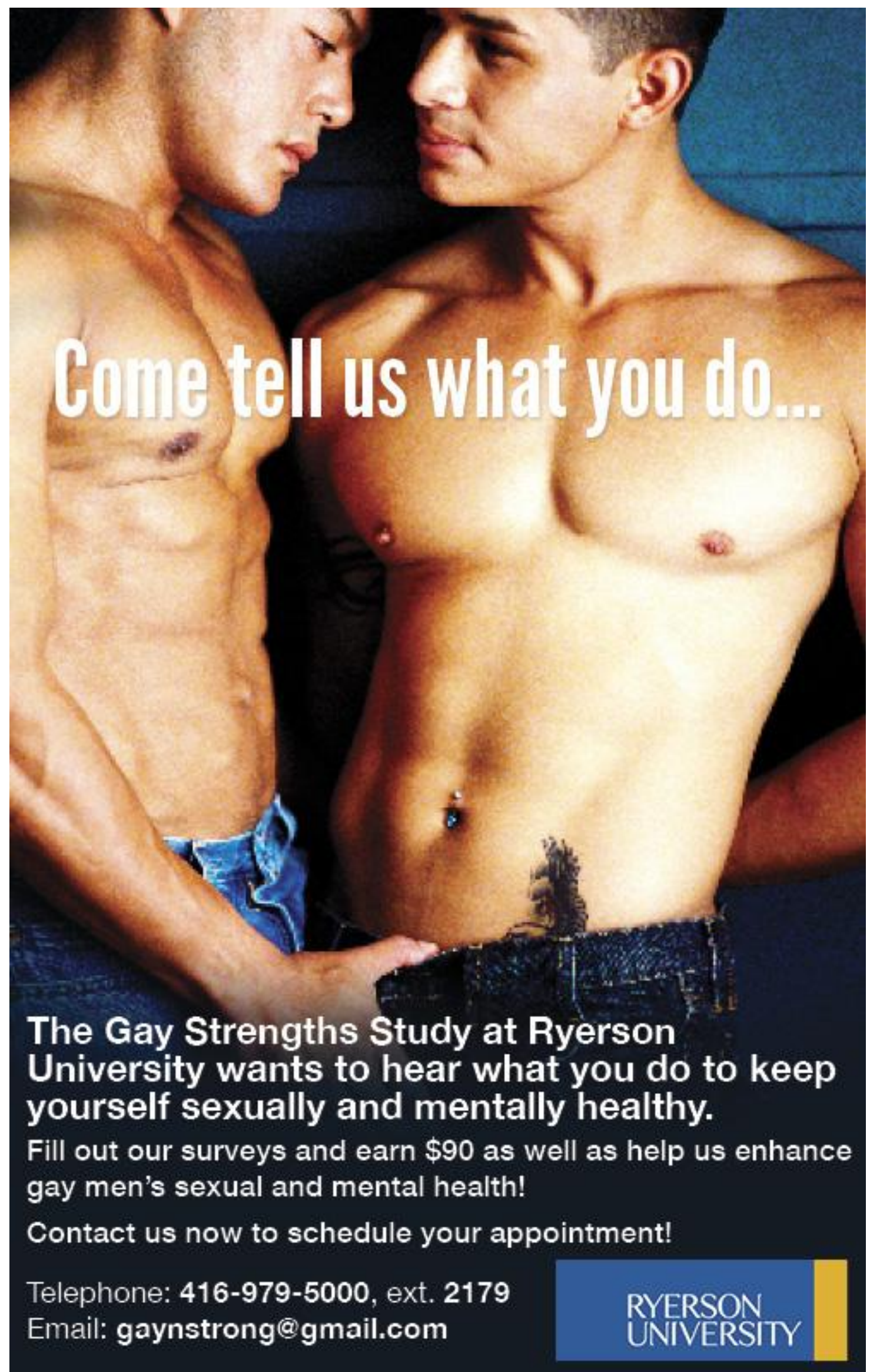


Appendix B

Study Questionnaires

\section{Socio-Demographic Questionnaire}

Instructions: Here are some basic questions about YOU. Please do not attach your name to this or any other sheet. Remember, all of your answers are confidential and you can not be identified by any of the pieces of information you provide on this, or any other sheet in the questionnaire package.

Today's Date

Date of Birth

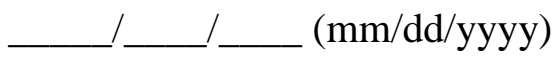

Age (in years)

Please check the appropriate box or boxes for the following questions:

My gender is
Male
Transman
2-spirited
Other (please specify)

How would you describe your sexual orientation? (Please check one of the following)

Gay or homosexual

Bisexual

Straight or heterosexual

2-spirited

$\square$ Other (please specify)

What is your employment status?

Full time employed

Part time employed

Self-employed

Housewife/husband

Unemployed

Retired

Other (please specify) 
What is the highest level of education you have reached/completed?
Did not attend high school
Some high school education
High school diploma
Some university, college or technical school education
Bachelor's degree, college diploma, or technical certificate
Some graduate or professional school
$\square$ Graduated graduate or professional school

Annual income: Please indicate which of the following best represents your annual income.

Under $\$ 20,000$

$\square \quad \$ 20,000-\$ 39,999$

$\square \$ 40,000-\$ 59,999$

$\square \$ 60,000-\$ 79,999$

$\square$ Over $\$ 80,000$

\section{Religion:}

Please indicate the religion of which you were raised:

\section{Catholic}

Protestant (e.g. United Church, Anglican, Lutheran, Presbyterian)

Evangelical Protestant (e.g. Baptist, Jehovah's Witness, Pentecostal, $7^{\text {th }}$ Day Adventist)

Eastern Orthodox

Christian - Other (Please specify)

Jewish

Islamic

Hindu

Sikh

Buddhist

Agnostic

Spiritual, but I do not believe in a God

None

Other (please specify) 
Please indicate the religion you currently practice:

Catholic

Protestant (e.g. United Church, Anglican, Baptist, Lutheran, Presbyterian)

Evangelical Protestant (e.g. Baptist, Jehovah's Witness, Pentecostal, $7^{\text {th }}$ Day Adventist)

Eastern Orthodox

Christian - Other (Please specify)

Jewish

Islamic

Hindu

Sikh

Buddhist

Agnostic

Spiritual, but I do not believe in a God

None

Other (please specify)

Ethnic Background: What ethnicity do you identify with? (Check as many as apply to you):

African (e.g., Nigeria, Ghana, Ethiopia)

African-Caribbean (i.e., from the Caribbean and of Black/African descent)

Indo-Caribbean (i.e., from the Caribbean and of South Asian descent)

Other Caribbean (i.e., from the Caribbean and of other ethnic descent)

South Asian (e.g., India, Pakistan, Bangladesh, Sri Lanka)

East Asian (e.g., Hong Kong, China, Japan, Korea)

Southeast Asian (e.g., Singapore, Malaysia, Thailand, Cambodia, Philippines)

Middle Eastern or North African (e.g., Iran, Israel, Egypt, Morocco)

Latin American

Aboriginal/Métis/Inuit

White - British (e.g., England, Ireland, Scotland, Wales)

White - French

White - Other European (e.g., German, Italian, Russian, Portuguese, etc.)

Other (please specify)

In which country were you born?

How long have you lived in Canada?

Which country were your parents born in?

Mother Father

Which country do your parents live in?

Mother

Father 
Please indicate who (if anyone) you live with (Check as many as apply to you)

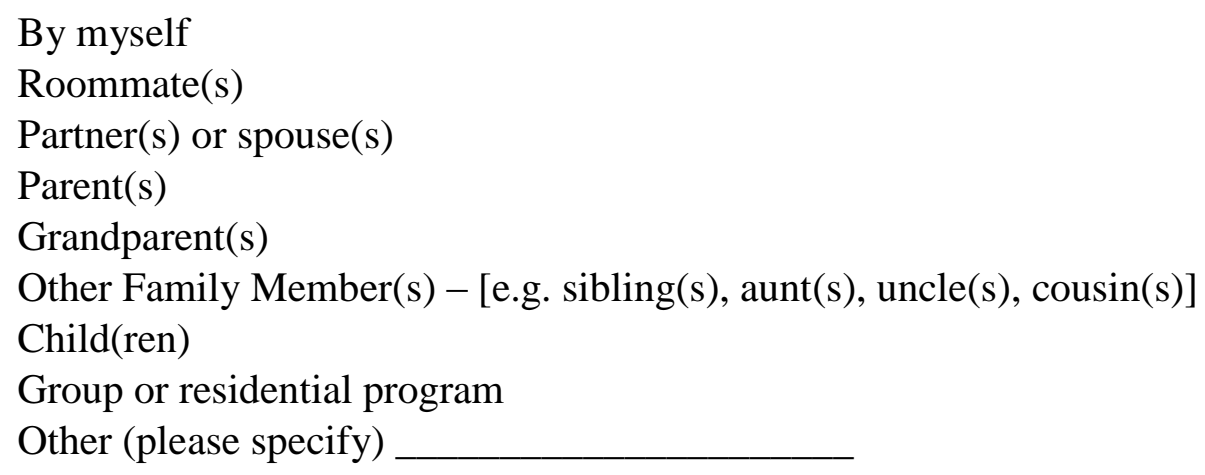

What is your current relationship status? Please check off all that apply.

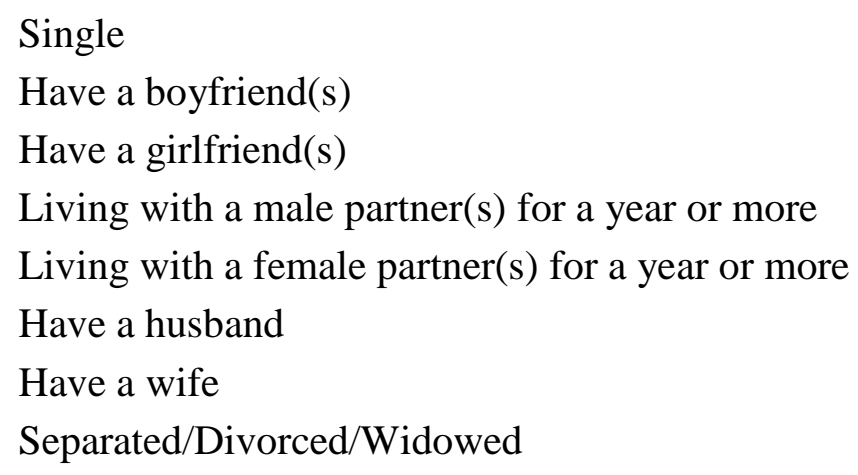

With which sex role do you most identify?

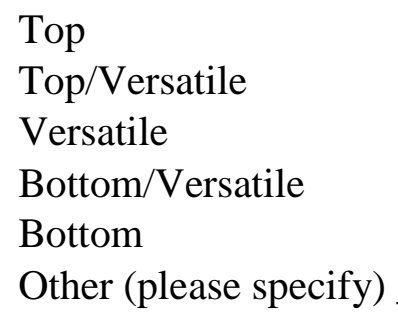

Are you circumcised?

$$
\begin{aligned}
& \square \text { Yes } \\
& \square \text { No }
\end{aligned}
$$

At what age were you circumcised?

Birth (less than one year old)

Child (between $1-17$ years old)

Adult (over the age of 18). Please specify age

Have you ever taken an HIV test? (Check one)
Yes
No
I don’t know 
What is your HIV status?

HIV-negative

HIV-positive

I do not know my HIV status

Other (please specify)

If you have been tested for HIV, were any of these tests mandatory (such as for immigration or work purposes?)

\section{Yes}

No

I have never been tested

\section{Internalized Homophobia Scale}

How comfortable do you feel about being gay?

\begin{tabular}{|ccccccccccc|}
\hline 1 & 2 & 3 & 4 & 5 & 6 & 7 & 8 & 9 & 10 \\
\hline $\begin{array}{c}\text { Extremely } \\
\text { Uncomfortable }\end{array}$ & & & & & & & & & $\begin{array}{c}\text { Very } \\
\text { Comfortable }\end{array}$ \\
\hline
\end{tabular}

Please rate your level of agreement with the following statements:

\begin{tabular}{|c|c|c|c|c|}
\hline 1 & 2 & 3 & 4 & 5 \\
\hline Strongly Disagree & Disagree & Neutral & Agree & $\begin{array}{c}\text { Strongly } \\
\text { Agree }\end{array}$ \\
\hline
\end{tabular}

1. I often feel it best to avoid personal involvement with other

$\begin{array}{lllll}1 & 2 & 3 & 4 & 5\end{array}$
gay/bisexual men

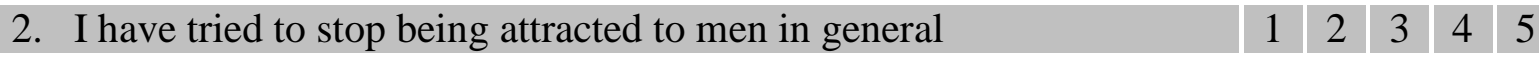

3. If someone offered me the chance to be completely heterosexual, I $\quad \begin{array}{llllll}1 & 2 & 3 & 4 & 5\end{array}$ would accept the chance.

\begin{tabular}{l|l|l|l|l|l|} 
4. I wish I weren't gay/bisexual. & 1 & 2 & 3 & 4 & 5
\end{tabular}

5. I feel alienated from myself because of being gay/bisexual. $\quad \begin{array}{lllllll} & 1 & 2 & 3 & 4 & 5\end{array}$

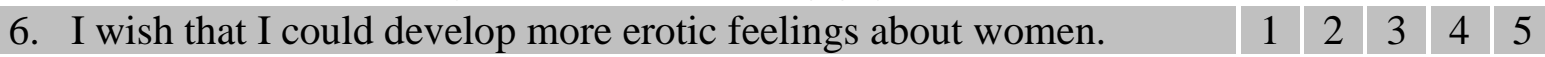

7. I feel that being gay/bisexual is a personal shortcoming for me. $\quad \begin{array}{lllllll}1 & 2 & 3 & 4 & 5\end{array}$

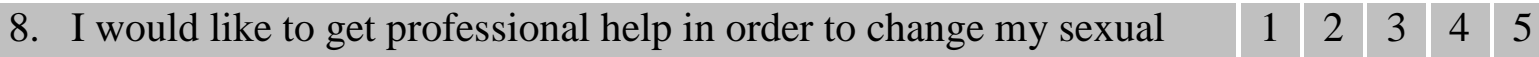
orientation from gay/bisexual to straight.

9. I have tried to become more sexually attracted to women. $\quad 1 \quad 2 \quad 3 \quad 4 \quad 5$ 


\section{STICSA - Trait}

Below is a list of statements which can be used to describe how people feel. Beside each statement are four numbers which indicate the degree with which each statement is self-descriptive of your mood in general. Please read each statement carefully and circle the number which best indicates how often, IN GENERAL, the statement is true of you.

\begin{tabular}{|c|c|c|c|}
\hline 1 & 2 & 3 & 4 \\
\hline Almost Never & Occasionally & Often & Almost always \\
\hline
\end{tabular}

1. My heart beats fast.

$\begin{array}{llll}1 & 2 & 3 & 4\end{array}$

2. My muscles are tense.

$\begin{array}{llll}1 & 2 & 3 & 4\end{array}$

3. I feel agonized over my problems.*

$\begin{array}{llll}1 & 2 & 3 & 4\end{array}$

4. I think that others won't approve of me.*

$\begin{array}{llll}1 & 2 & 3 & 4\end{array}$

5. I feel like I'm missing out on things because I can't make up my mind soon enough.*

$\begin{array}{llll}1 & 2 & 3 & 4\end{array}$

6. I feel dizzy.

$\begin{array}{llll}1 & 2 & 3 & 4\end{array}$

7. My muscles feel weak.

$\begin{array}{llll}1 & 2 & 3 & 4\end{array}$

8. I feel trembly and shaky.

$\begin{array}{llll}1 & 2 & 3 & 4\end{array}$

9. I picture some future misfortune.*

$\begin{array}{llll}1 & 2 & 3 & 4\end{array}$

10. I can't get some thought out of my mind.*

$\begin{array}{llll}1 & 2 & 3 & 4\end{array}$

11. I have trouble remembering things.*

$\begin{array}{llll}1 & 2 & 3 & 4\end{array}$

12. My face feels hot.

$\begin{array}{llll}1 & 2 & 3 & 4\end{array}$

13. I think that the worst will happen.*

$\begin{array}{llll}1 & 2 & 3 & 4\end{array}$

14. My arms and legs feel stiff.

$\begin{array}{llll}1 & 2 & 3 & 4\end{array}$

15. My throat feels dry.

16. I keep busy to avoid uncomfortable thoughts.*

$\begin{array}{llll}1 & 2 & 3 & 4\end{array}$

17. I cannot concentrate without irrelevant thoughts intruding.*

$\begin{array}{llll}1 & 2 & 3 & 4\end{array}$

18. My breathing is fast and shallow.

$\begin{array}{llll}1 & 2 & 3 & 4\end{array}$

19. I worry that I cannot control my thoughts as well as I would like to.*

$\begin{array}{llll}1 & 2 & 3 & 4\end{array}$

20. I have butterflies in the stomach.

$\begin{array}{llll}1 & 2 & 3 & 4\end{array}$

21. My palms feel clammy.

$\begin{array}{llll}1 & 2 & 3 & 4\end{array}$

Note: Cognitive anxiety subscale items are identified with an asterisk $\left(^{*}\right)$. 


\section{IIEF-MSM}

INSTRUCTIONS: Each of the following questions has several possible answers. Check off the answer that best describes your own situation over the past 4 weeks. Please answer the following questions as honestly and clearly as possible. Your responses will be kept completely confidential. In answering these questions, the following definitions apply:

Sexual activity can include caressing, foreplay, masturbation, and intercourse.

Active Anal intercourse is defined as penetrating (entry) your partner's anus.

Passive Anal intercourse is defined as being penetrated (entry) by your partner.

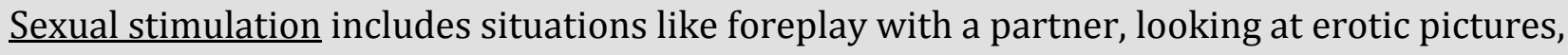
sexual fantasy, etc.

Sexual desire or interest is a feeling that includes wanting to have a sexual experience, feeling receptive to a partner's sexual initiation, and thinking or fantasizing about having sex.

Ejaculate is defined as the ejection of semen from the penis (or the feeling of this)

\section{How often were you able to get an erection during sexual activity?}

0 No sexual activity

$\square 1$ Almost never/never

$\square 2$ A few times (much less than half the time)

$\square 3$ Sometimes (about half the time)

$\square 4$ Most times (much more than half the time)

$\square 5$ Almost always/always

2. When you had erections with sexual stimulation, how often were your erections hard enough for penetration?

0 No sexual activity

$\square 1$ Almost never/never

$\square 2$ A few times (much less than half the time)

$\square 3$ Sometimes (about half the time)

$\square 4$ Most times (much more than half the time)

$\square 5$ Almost always/always

3. Have you had, or attempted to have, active anal intercourse (i.e., where you penetrated or attempted to penetrate your partner)?

0 No

$\square 1$ Yes 
4. When you attempted active anal intercourse, how often were you able to penetrate (enter) your partner?

0 Did not attempt intercourse

$\square 1$ Almost never/never

$\square 2$ A few times (much less than half the time)

$\square 3$ Sometimes (about half the time)

$\square 4$ Most times (much more than half the time)

$\square 5$ Almost always/always

5. During active anal intercourse, how often how were you able to maintain your erection after you had penetrated (entered) your partner?

0 Did not attempt intercourse

$\square$ Almost never/never

$\square 2 \mathrm{~A}$ few times (much less than half the time)

$\square 3$ Sometimes (about half the time)

$\square 4$ Most times (much more than half the time)

$\square 5$ Almost always/always

6. During active anal intercourse, how difficult was it to maintain your erection to completion of intercourse?

0 Did not attempt intercourse

$\square 1$ Extremely difficult

$\square 2$ Very difficult

$\square 3$ Difficult

$\square 4$ Slightly difficult

$\square 5$ Not difficult

7. Have you had, or attempted to have, passive anal intercourse (i.e., where you were penetrated by your partner)?

0 No

8. During passive anal intercourse, how often were you able to maintain your erection after you had been penetrated (entered) by your partner?

0 Did not attempt intercourse

$\square$ Almost never/never

$\square 2$ A few times (much less than half the time)

$\square 3$ Sometimes (about half the time)

$\square 4$ Most times (much more than half the time)

$\square 5$ Almost always/always 
9. During passive anal intercourse, how difficult was it to maintain your erection to completion of intercourse?

$\square 0$ Did not attempt intercourse

1 Extremely difficult

2 Very difficult

$\square 3$ Difficult

$\square 4$ Slightly difficult

$\square 5$ Not difficult

10. During non-intercourse sexual activity (e.g., masturbation, oral sex), how often were you able to maintain your erection until the completion of sexual activity?

0 Did not attempt intercourse

$\square 1$ Almost never/never

$\square 2 \mathrm{~A}$ few times (much less than half the time)

$\square 3$ Sometimes (about half the time)

$\square 4$ Most times (much more than half the time)

$\square 5$ Almost always/always

11. How many times have you had or attempted to have sexual intercourse or other sexual activity?

0 No attempts

1 One to two attempts

2 Three to four attempts

3 Five to six attempts

$\square 4$ Seven to ten attempts

$\square 5$ Eleven+ attempts

12. When you had or attempted to have sexual intercourse or other sexual activity, how often was it satisfactory for you?

0 Did not attempt intercourse

$\square 1$ Almost never/never

$\square 2 \mathrm{~A}$ few times (much less than half the time)

$\square 3$ Sometimes (about half the time)

$\square 4$ Most times (much more than half the time)

$\square 5$ Almost always/always

13. How much have you enjoyed sexual intercourse or other sexual activity?

$\square 0$ No intercourse

$\square 1$ No enjoyment

$\square 2$ Not very enjoyable

$\square 3$ Fairly enjoyable

$\square 4$ Highly enjoyable

$\square 5$ Very highly enjoyable 
14. When you had sexual stimulation or intercourse, how often did you ejaculate?

0 No sexual stimulation/intercourse

$\square 1$ Almost never/never

$\square 2$ A few times (much less than half the time)

$\square 3$ Sometimes (about half the time)

$\square 4$ Most times (much more than half the time)

$\square 5$ Almost always/always

15. When you had sexual stimulation or intercourse, how often did you have the feeling of orgasm or climax with or without ejaculation?

0 No sexual stimulation/intercourse

$\square 1$ Almost never/never

$\square 2$ A few times (much less than half the time)

$\square 3$ Sometimes (about half the time)

$\square 4$ Most times (much more than half the time)

$\square 5$ Almost always/always

16. How often have you felt sexual desire?

$\square 1$ Almost never/never

$\square 2 \mathrm{~A}$ few times (much less than half the time)

$\square 3$ Sometimes (about half the time)

$\square 4$ Most times (much more than half the time)

$\square 5$ Almost always/always

17. How would you rate your level of sexual desire?

1 Very low/ none at all

$\square 2$ Low

$\square 3$ Moderate

$\square 4$ High

$\square 5$ Very high

18. How satisfied have you been with your overall sex life?

1 Very dissatisfied

$\square 2$ Moderately dissatisfied

$\square 3$ Equally satisfied and dissatisfied

$\square 4$ Moderately satisfied

$\square 5$ Very satisfied 
19. How satisfied have you been with your sexual relationship with your regular partner?

$\square 1$ Very dissatisfied

$\square 2$ Moderately dissatisfied

$\square 3$ Equally satisfied and dissatisfied

$\square 4$ Moderately satisfied

$\square 5$ Very satisfied

20. How do you rate your confidence that you could get and keep an erection?

$\square 1$ Very low

$\square 2$ Low

$\square 3$ Moderate

$\square 4$ High

$\square 5$ Very high

21. How often do you wake up with an erection?

0 None of the time

1 Almost never/never

$\square 2 \mathrm{~A}$ few times (much less than half the time)

$\square 3$ Sometimes (about half the time)

$\square 4$ Most times (much more than half the time)

$\square 5$ Almost always/always

22. When you masturbated, how often could you get an erection?

$\square$ No masturbation

$\square 1$ Almost never/never

$\square 2 \mathrm{~A}$ few times (much less than half the time)

$\square 3$ Sometimes (about half the time)

$\square 4$ Most times (much more than half the time)

$\square 5$ Almost always/always 
Appendix C

Informed Consent Form

\section{Consent Agreement}

\section{Protective Factors Against HIV Risk Behaviour Among Gay and Bisexual Men: A Longitudinal Study}

You are being asked to participate in a research study. Before you give your consent to be a volunteer, it is important that you read the following information and ask as many questions as necessary to be sure you understand what you will be asked to do.

Principal Investigators: Trevor A. Hart, Ph.D., C. Psych \& Barry D. Adam, Ph.D.

\section{Purpose of the Study:}

The purpose of this study is to identify the traits and strategies used during sexual activity by men who have sex with men.

\section{Description of the Study:}

You are eligible to participate in the study if you:

- Are an HIV-negative male who has had any sexual activity with another man in the past 6 months.

- Speak and understand English

- Anticipate that you will be able to attend all assessment sessions

If you meet inclusion criteria and choose to participate in this study, you will be required to attend three (baseline, 3-month follow-up, \& 6-month follow-up) 1-hour sessions during which you will be asked to fill out a questionnaire package. A smaller group of participants will be selected to attend follow-up in-person interviews.

Questionnaire and interview questions will focus on experiences you may have had throughout childhood, adolescence, and adulthood. Some questions will ask you about your sexual history and sexual behaviours, as well as your experience particularly as a man who has sex with men.

Note: You may decline to answer any question. You may withdraw from the session at any time by indicating to the assessor that you do not wish to continue. Should you choose to withdraw from the study, all data generated as a result of your participation will be immediately destroyed.

Your decision to participate will not affect already-standing relationships at Ryerson or with any supporting agencies.

Risks and Discomforts: There are no physical risks involved in participating in this study. It is possible that some of the questions asked in this study might make you feel uncomfortable. If you are uncomfortable with any portions of the study, please notify the research assistant. Also, please be advised that you can withdraw from the study at any time if you wish to do so, without any consequences. 
Benefits of the Research and Benefits to You: Your participation in this study will help us to understand the health risk behaviours of men who have sex with men, and will help us to develop effective interventions to lower these risks in the gay and bisexual men's community.

Withdrawal from the Study: Your participation in the study is completely voluntary. You may choose to withdraw at any time. Your decision not to participate will not influence your relationship with the researchers involved in the study or with Ryerson University, now or in the future. You can stop participating in the study at any time. If you don't complete all portions of the study, you will still be reimbursed for the portions you have completed. However, if you decide you would no longer like to be a part of the study, your data will not be used.

Confidentiality: All information you provide during the research will be kept private. Your name will not appear in any report or publication of the research. The questionnaires and interview notes will be kept in a locked filing cabinet in a locked office. We will keep this consent form and the participation list separate from the questionnaires and interview notes. All questionnaires and interview notes will be destroyed 10 years after the study is over. We will keep your records as private as the law allows.

We will keep all the facts about you private. We would have to breach your confidentiality only:

a) If you intend to harm yourself,

b) If you intend on harming someone else,

c) If you inform us that a child is currently at risk for abuse or neglect,

d) If you report sexual abuse by a health care practitioner, or

e) If the records are subject to a subpoena by the courts (records can be opened by a specific court order but it is highly unlikely that this would ever happen).

We will use a study number rather than your name on study records. No one will see your name and other facts that might point to you when we present this study or publish its results.

\section{Compensation/Cost:}

You will be compensated to participate in this study as follows:

- 1-hour baseline session

@ $\$ 30.00$

- 1-hour 3-month follow-up session

@ \$30.00

- 1-hour 6-month follow-up session

@ $\$ 30.00$

Questions About the Research? If you have questions about the research in general or about your role in the study, please feel free to contact:

\section{Dr. Trevor Hart}

Principal Investigator/Director

HIV Prevention Lab, Ryerson University

416-979-5000 extension 619

E-mail: trevor.hart@ryerson.ca
Dr. Barry Adam

Co-Principal Investigator

University of Windsor

416-642-6486 extension 2242

E-mail: adam@uwindsor.ca 
This research has been reviewed by the Ryerson University's Research Ethics Board and conforms to the standards of the Canadian Tri-Council Research Ethics guidelines. If you have any questions about this process, or about your rights as a participant in the study please contact:

Toni Fletcher

Research Ethics Board

Ryerson University

416-979-5000 extension 7112

E-mail: toni.fletcher@ryerson.ca

\section{Agreement:}

Your signature below means that you have read the information in this agreement and have had a chance to ask any questions you have about the study. Your signature also means that you agree to participate in the study and have been told that you can change your mind at any time. You have been given a copy of this agreement.

You have been told that by signing this consent agreement you are not giving up any of your legal rights.

Name of Participant (please print)

Signature of Participant

Date

Signature of Investigator

Date

Please indicate if you would like to receive an electronic version of the results/findings at the end of the study:

Yes, I would like to receive an electronic copy of the results/findings.

No, I would not like to receive an electronic copy of the results/findings. 


\title{
Appendix D
}

\author{
Debriefing Form
}

\section{Ryerson University Debriefing Form}

Thank you for participating in the Gay Strengths Study! We would like to take this opportunity to remind you that this study asked questions about your sexual history and sexual behaviours, as well as your experience particularly as a man who has sex with men. This study aims to identify sexual strategies used by gay and bisexual men that lead to various sexual risk outcomes.

We would also like to take this opportunity to inform you of clinics available in the Greater Toronto Area (GTA) and surrounding areas where you can go to be tested for HIV and other STIs (sexually transmitted infections), should you wish to do so. Each of the clinics listed offer free and anonymous testing centres for HIV and STIs. Please be sure to contact the centres if you would like to ask about their confidentiality policies. Here is a list of available centres in the GTA and surrounding area:

Central Region

Simcoe Muskoka District Health

15 Sperling Dr., Barrie

(705) $721-7520$

(877) $721-7520 \times 8376$

Greater Toronto Area:

Anishnawbe Health Toronto

225 Queen St. E., Toronto

(416) $360-0486$

Bay Centre for Birth Control, Regional Women's Health Centre 790 Bay St., Toronto, $8^{\text {th }}$ Floor

(416) $351-3700$

Birth Control \& Sexual Health Centre 960 Lawrence Ave West, Suite 403

(416) 789-4541

Brampton- Healthy Sexuality Clinic 150 Central Park Dr., Suite 09, Brampton (905) 791-5905

Caledon - Healthy Sexuality Clinic

18 King Street East, Bolton

(905) 791-5905

Centre Francophone de Toronto

22 College St., Toronto

(416) $922-2672$

Hassle Free Clinic

556 Church St., Toronto

(416)- 922-0603 (for men)

(416) 922- 0566 (for women)

\author{
Simcoe Muskoka District Health \\ Men Only Drop-In Clinic \\ 80 Bradford Street, Unit 403, Barrie \\ Rapid Testing, Tuesday, 3-6pm \\ Planned Parenthood \\ 36-B Prince Arthur Ave., Toronto \\ (416) 961-0113 (for youth aged 13-29) \\ East Mississauga - Peel Public Health Clinic \\ 325 Central Parkway West, Unit 21 Mississauga \\ (905) 270-0587 \\ West Mississauga - Healthy Sexuality Clinic \\ 2227 South Millway, Mississauga \\ (905) 820-3663 \\ Queen West Community Health Centre \\ 168 Bathurst St., Toronto \\ (416) 703-8482 \\ Rexdale Community Health Centre \\ Jamestown site \\ 1701 Martin Grove Road, Etobicoke \\ (647) 288-0282 \\ Scarborough Centre for Healthy Communities \\ Community Health Centre \\ 2660 Eglinton Ave East, Scarborough \\ (416) 642-9445 \\ The Works \\ 277 Victoria St., Ground Floor, Toronto \\ (416) 392-052 \\ Walk-in, $11 \mathrm{am}-4 \mathrm{pm}$
}

In order to schedule your future study sessions, please notify us if your contact information changes over the next 6 months. Feel free to contact us at any time by telephone or email.

Email: gaynstrong@gmail.com

Phone: 416-979-5000, ext. 2179

Facebook: facebook.com/gaynstrong

Your next session will be: 


\section{References}

Abrahamson, D. J., Barlow, D, H., Sakheim, D. K., Beck, J. G., \& Athanasiou, R. (1985). Effects of distraction on sexual responding in functional and dysfunctional men. Behavior Therapy, 16, 503-515. doi: 10.1016/S0005-7894(85)80028-9

Adam, B. D., Husbands, W., Murray, J., \& Maxwell, J. (2008). Circuits, networks, and HIV risk management. AIDS Education \& Prevention, 20(5), 420-434. doi:

10.1521/aeap.2008.20.5.420

Allen, D. J., \& Oleson, T. (1999). Shame and internalized homophobia in gay men. Journal of Homosexuality, 37, 33-43. doi:10.1300/J082v37n03_03

American Psychiatric Association. (2013). Diagnostic and statistical manual of mental disorders ( $5^{\text {th }}$ ed.). Washington, DC: American Psychiatric Association.

Araujo, A. B., Durante, R., Feldman, H. A., Goldstein, I., \& McKinlay, J. B. (1998). The relationship between depressive symptoms and male erectile dysfunction: Cross-sectional results from the Massachusetts Male Aging Study. Psychosomatic Medicine, 60(4), 458465.

Asboe, D., Catalan, J., Mandalia, S., Dedes, N., Florence, E., Schrooten, W., ... \& Colebunders, R. (2007). Sexual dysfunction in HIV-positive men is multi-factorial: A study of prevalence and associated factors. AIDS Care, 19, 955-965. doi: $10.1080 / 09540120701209847$

Bancroft, J. \& Janssen, E. (2000). The dual control model of male sexual response: A theoretical approach to centrally mediated erectile dysfunction. Neuroscience \& Biobehavioural Reviews, 24, 571-579. doi: 10.1016/S0149-7634(00)00024-5 
Bancroft, J., Carnes, L., Janssen, E., Goodrich, D., \& Long, J. S. (2005). Erectile and ejaculatory problems in gay and heterosexual men. Archives of Sexual Behavior, 34, 285-297. doi: $10.1007 / \mathrm{s} 10508-005-3117-7$

Barlow, D. H. (1986). Causes of sexual dysfunction: The role of anxiety and cognitive interference. Journal of Consulting and Clinical Psychology, 54, 140-148. doi:10.1037/0022-006X.54.2.140

Barlow, D. H., Sakheim, D. K., \& Beck, J. G. (1983). Anxiety increases sexual arousal. Journal of Abnormal Psychology, 92, 49-54. doi:10.1037/0021-843X.92.1.49

Baron, R. M., \& Kenny, D. A. (1986). The moderator-mediator variable distinction in social psychological research: Conceptual, strategic, and statistical considerations. Journal of Personality and Social Psychology, 51, 1173-1182. doi: 10.1037/0022-3514.51.6.1173

Beck, J. G., \& Barlow, D. H. (1984). Current conceptualizations of sexual dysfunction: A review and an alternative perspective. Clinical Psychology Review, 4, 363-378. doi:10.1016/0272-7358(84)90017-5

Beck, J. G., \& Barlow, D. H. (1986a). The effects of anxiety and attentional focus on sexual responding-I. Cognitive and affective patterns in erectile dysfunction. Behaviour Research and Therapy, 24, 9-17. doi:10.1016/0005-7967(86)90144-0

Beck, J. G., \& Barlow, D. H. (1986b). The effects of anxiety and attentional focus on sexual responding-II. Cognitive and affective patterns in erectile dysfunction. Behaviour Research and Therapy, 24, 19-26. doi:10.1016/0005-7967(86)90145-2

Beck, J. G., Barlow, D. H., \& Sakheim, D. K. (1983). The effects of attentional focus and partner arousal on sexual responding in functional and dysfunctional men. Behaviour Research and Therapy, 21, 1-8. doi:10.1016/0005-7967(83)90120-1 
Breyer, B. N., Smith, J. F., Eisenberg, M. L., Ando, K. A., Rowen, T. S., \& Shindel, A. W. (2010). The impact of sexual orientation on sexuality and sexual practices in North American medical students. The Journal of Sexual Medicine, 7, 2391-2400. doi: 10.1111/j.1743-6109.2010.01794.x

Byers, E. S. (2005). Relationship satisfaction and sexual satisfaction: A longitudinal study of individuals in long- term relationships. Journal of Sex Research, 42, 113-118. doi: $10.1080 / 00224490509552264$

Cranston-Cuebas, M. A., \& Barlow, D. H. (1990). Cognitive and affective contributions to sexual functioning. Annual Review of Sex Research, 1, 119-161. doi:10.1080/10532528.1990.10559858

Chivers, M. L., Seto, M. C., Lalumiere, M. L., Laan, E., \& Grimbos, T. (2010). Agreement of self-reported and genital measures of sexual arousal in men and women: A metaanalysis. Archives of Sexual Behavior, 39, 5-56. doi: 10.1007/s10508-009-9556-9

Corona, G., Ricca, V., Bandini, E., Mannucci, E., Petrone, L., Fisher, A. D., ... \& Maggi, M. (2008). Association between psychiatric symptoms and erectile dysfunction. The Journal of Sexual Medicine, 5, 458-468. doi: 10.1111/j.1743-6109.2007.00663.x

Cove, J., \& Boyle, M. (2002). Gay men's self-defined sexual problems, perceived causes and factors in remission. Sexual and Relationship Therapy, 17, 137-147. doi:10.1080/14681990220121257

Cove, J., \& Petrak, J. (2004). Factors associated with sexual problems in HIV-positive gay men. International Journal of STD \& AIDS, 15, 732-736.

doi: 10.1258/0956462042395221 
Coyne, K., Mandalia, S., McCullough, S., Catalan, J., Noestlinger, C., Colebunders, R., \& Asboe, D. (2010). The International Index of Erectile Function: Development of an adapted tool for use in HIV- positive men who have sex with men. The Journal of Sexual Medicine, 7, 769-774. doi: 10.1111/j.1743-6109.2009.01579.x

Davison, S. L., Bell, R. J., LaChina, M., Holden, S. L., \& Davis, S. R. (2009). The relationship between self- reported sexual satisfaction and general well- being in women. The Journal of Sexual Medicine, 6, 2690-2697. doi: 10.1111/j.1743-6109.2009.01406.x

Dunn, K. M., Croft, P. R., \& Hackett, G. I. (1999). Association of sexual problems with social, psychological, and physical problems in men and women: A cross sectional population survey. Journal of Epidemiology and Community Health, 53(3), 144-148.

doi:10.1136/jech.53.3.144

Ende, A. R., Re III, V. L., DiNubile, M. J., \& Mounzer, K. (2006). Erectile dysfunction in an urban HIV-positive population. AIDS Patient Care \& STDs, 20, 75-78. doi:10.1089/apc.2006.20.75.

Endler, N. S., \& Kocovski, N. L. (2001). State and trait anxiety revisited. Journal of Anxiety Disorders, 15, 231-245. doi: 10.1016/S0887-6185(01)00060-3

Engel, G. L. (1977). The need for a new medical model: A challenge for biomedicine. Science, 196, 129-136. doi: 10.1126/science.847460

Field, A. (2009). Discovering statistics using SPSS (3 ${ }^{\text {rd }}$ ed.). London: Sage.

Fisher, W. A., Rosen, R. C., Eardley, I., Sand, M., \& Goldstein, I. (2005). Sexual experience of female partners of men with erectile dysfunction: The Female Experience of Men's Attitudes to Life Events and Sexuality (FEMALES) study. The Journal of Sexual Medicine, 2, 675-684. doi: 10.1111/j.1743-6109.2005.00118.x 
Fritz, M. S., \& MacKinnon, D. P. (2007). Required sample size to detect the mediated effect. Psychological Science, 18, 233-239. doi: 10.1111/j.1467-9280.2007.01882.x

Frost, D. M., \& Meyer, I. H. (2009). Internalized homophobia and relationship quality among lesbians, gay men, and bisexuals. Journal of Counseling Psychology, 56, 97-109. doi:10.1037/a0012844

Graham, C. A., Crosby, R., Yarber, W. L., Sanders, S. A., McBride, K., Milhausen, R. R., \& Arno, J. N. (2006). Erection loss in association with condom use among young men attending a public STI clinic: Potential correlates and implications for risk behaviour. Sexual Health, 3, 255-260. doi: 10.1071/SH06026

Grös, D. F., Antony, M. M., Simms, L. J., \& McCabe, R. E. (2007). Psychometric properties of the State-Trait Inventory for Cognitive and Somatic Anxiety (STICSA): Comparison to the State-Trait Anxiety Inventory (STAI). Psychological Assessment, 19, 369-381. doi: $10.1037 / 1040-3590.19 .4 .369$

Hallfors, D., Khatapoush, S., Kadushin, C., Watson, K., \& Saxe, L. (2000). A comparison of paper vs computer-assisted self interview for school alcohol, tobacco, and other drug surveys. Evaluation and Program Planning, 23, 149-155. doi: 10.1016/S01497189(00)00011-2

Hart, T. A., Moskowitz, D., Cox, C., Li, X., Ostrow, D. G., Stall, R. D., ... \& Plankey, M. (2012). The cumulative effects of medication use, drug use, and smoking on erectile dysfunction among men who have sex with men. The Journal of Sexual Medicine, 9, 1106-1113. doi: 10.1111/j.1743-6109.2011.02648.x.

Hart, T. A., Wolitski, R. J., Purcell, D. W., Gomez, C., Halkitis, P., \& the Seropositive Urban Men's Study Team. (2003). Sexual behavior among HIV-positive men who have sex with 
men: What's in a label? Journal of Sex Research, 40, 179-188. doi:

$10.1080 / 00224490309552179$

Hatzenbuehler, M. L., Nolen-Hoeksema, S., \& Erickson, S. J. (2008). Minority stress predictors of HIV risk behavior, substance use, and depressive symptoms: Results from a prospective study of bereaved gay men. Health Psychology, 27, 455-462.

doi: 10.1037/0278-6133.27.4.455

Hayes, A. F. (2009). Beyond Baron and Kenny: Statistical mediation analysis in the new millennium. Communication Monographs, 76(4), 408-420. doi:10.1080/03637750903310360

Hayes, A. F. (2013). Introduction to mediation, moderation, and conditional process analysis. New York: Guilford.

Hayes, A. F. (2014, March). Mediation, moderation, and conditional process analyses: Longitudinal panel designs. Workshop attended at the University of Toronto.

Herek, G. M., Cogan, J. C., Gillis, J. R., \& Glunt, E. K. (1997). Correlates of internalized homophobia in a community sample of lesbians and gay men. Journal of the Gay and Lesbian Medical Association, 2, 17-26.

Herek, G. M., Gillis, J. R., \& Cogan, J. C. (2009). Internalized stigma among sexual minority adults: Insights from a social psychological perspective. Journal of Counseling Psychology,56, 32-43. doi:10.1037/a0014672

Herek, G. M., \& Glunt, E. K. (1995). Identity and community among gay and bisexual men in the AIDS era: Preliminary findings from the Sacramento Men's Health Study. In G. M. Herek \& B. Greene (Eds.), Psychological perspectives on lesbian and gay issues, Volume 2 (pp. 55-84). Thousand Oaks, CA: Sage. 
Hirshfield, S., Chiasson, M. A., Wagmiller Jr, R. L., Remien, R. H., Humberstone, M., Scheinmann, R., \& Grov, C. (2010). Sexual dysfunction in an internet sample of US men who have sex with men. The Journal of Sexual Medicine, 7, 3104-3114. doi: 10.1111/j.1743-6109.2009.01636.x

Igartua, K. J., Gill, K., \& Montoro, R. (2003). Internalized homophobia: A factor in depression, anxiety, and suicide in the gay and lesbian population. Canadian Journal of Community Mental Health, 22(2), 15-30.

Johnson, A. M., Copas, A. J., Erens, B., Mandalia, S., Fenton, K., Korovessis, C., ... \& Field, J. (2001). Effect of computer-assisted self-interviews on reporting of sexual HIV risk behaviours in a general population sample: A methodological experiment. AIDS, 15(1), 111-115.

Kaplan, H. S. (1974). The new sex therapy: Active treatment of sexual dysfunctions. New York: Routledge.

Kimmel, S. B., \& Mahalik, J. R. (2005). Body image concerns of gay men: The roles of minority stress and conformity to masculine norms. Journal of Consulting and Clinical Psychology, 73, 1185-1190. doi: 10.1037/0022-006X.73.6.1185

King, M., Semlyen, J., Tai, S. S., Killaspy, H., Osborn, D., Popelyuk, D., \& Nazareth, I. (2008). A systematic review of mental disorder, suicide, and deliberate self harm in lesbian, gay and bisexual people. BMC Psychiatry, 8, 70-87. doi: 10.1186/1471-244X-8-70

Kuyper, L., \& Vanwesenbeeck, I. (2011). Examining sexual health differences between lesbian, gay, bisexual, and heterosexual adults: The role of sociodemographics, sexual behavior characteristics, and minority stress. Journal of Sex Research, 48, 263-274. doi: $10.1080 / 00224491003654473$ 
Lacefield, K., \& Negy, C. (2012). Non-erotic cognitive distractions during sexual activity in sexual minority and heterosexual young adults. Archives of Sexual Behavior, 41, 391-400. doi: 10.1007/s10508-011-9792-7

Latini, D. M., Penson, D. F., Colwell, H. H., Lubeck, D. P., Mehta, S. S., Henning, J. M., \& Lue, T. F. (2002). Psychological impact of erectile dysfunction: Validation of a new health related quality of life measure for patients with erectile dysfunction. The Journal of Urology, 168, 2086-2091. doi: 10.1097/01.ju.0000034365.57110.b7

Laumann, E.O., Paik, A., \& Rosen, R.C. (1999). Sexual dysfunction in the United States: Prevalence and predictors. The Journal of the American Medical Association, 281, 537544. doi: $10.1001 /$ jama.281.6.537

Laumann, E. O., West, S., Glasser, D., Carson, C., Rosen, R., \& Kang, J. H. (2007). Prevalence and correlates of erectile dysfunction by race and ethnicity among men aged 40 or older in the United States: From the male attitudes regarding sexual health survey. The Journal of Sexual Medicine, 4, 57-65. doi: 10.1111/j.1743-6109.2006.00340.x

Levy, J. (1994). Impotence and its medical and psychosocial correlates: Results of Massachusetts Male Aging Study. Journal of Urology, 151, 54-61.

Mah, K., \& Binik, Y. M. (2001). The nature of human orgasm: A critical review of major trends. Clinical Psychology Review, 21, 823-856. doi: 10.1016/S0272-7358(00)00069-6

Masters, W.H., \& Johnson, V.E. (1966). Human sexual response. New York: Bantam Books. Masters, W. H., \& Johnson, V. E. (1970). Human sexual inadequacy. Boston: Little Brown. McCabe, M.P. (1997). Intimacy and quality of life among sexually dysfunctional men and women. Journal of Sex \& Marital Therapy, 23, 276-290. doi:10.1080/00926239708403932 
McCabe, M., Althof, S. E., Assalian, P., Chevret- Measson, M., Leiblum, S. R., Simonelli, C., \& Wylie, K. (2010). Psychological and interpersonal dimensions of sexual function and dysfunction. The Journal of Sexual Medicine, 7, 327-336. doi: 10.1111/j.17436109.2009.01618.x

McCabe, M. P., \& Cummins, R. A. (1997). Sexuality and quality of life among young people. Adolescence, 33(132), 761-773.

McKinlay, J. B. (2000). The worldwide prevalence and epidemiology of erectile dysfunction. International Journal of Impotence Research, 12, S6-S11. doi: 10.1038/sj.ijir.3900567

Meyer, I. H. (1995). Minority stress and mental health in gay men. Journal of Health and Social Behavior, 36(1), 38-56.

Meyer, I. H. (2003). Prejudice, social stress, and mental health in lesbian, gay, and bisexual populations: Conceptual issues and research evidence. Psychological Bulletin, 129, 674697.

Meyer, I. H., \& Dean, L. (1998). Internalized homophobia, intimacy, and sexual behavior among gay and bisexual men. In G. M. Herek (Ed.), Stigma and sexual orientation: Understanding prejudice against lesbians, gay men, and bisexuals (pp. 160-186). Thousand Oaks, CA, US: Sage Publications.

Millett, G. A., Peterson, J. L., Flores, S. A., Hart, T. A., Wilson, P. A., Rourke, S. B., ... \& Remis, R. S. (2012). Comparisons of disparities and risks of HIV infection in black and other men who have sex with men in Canada, UK, and USA: A meta-analysis. The Lancet, 380, 341-348. doi: 10.1016/S0140-6736(12)60899-X

Moskowitz, D. A., Rieger, G., \& Roloff, M. E. (2008). Tops, bottoms, and versatiles. Sexual and Relationship Therapy, 23, 191-202. doi: 10.1080/14681990802027259 
Musacchio, N. S., Hartrich, M., \& Garofalo, R. (2006). Erectile dysfunction and Viagra use: What's up with college-age males? Journal of Adolescent Health, 39, 452-454. doi: 10.1016/j.jadohealth.2005.12.021

Newcomb, M. E., \& Mustanski, B. (2010). Internalized homophobia and internalizing mental health problems: A meta-analytic review. Clinical Psychology Review, 30, 1019-1029. doi:10.1016/j.cpr.2010.07.003

Nicolosi, A., Laumann, E. O., Glasser, D. B., Brock, G., King, R., \& Gingell, C. (2006). Sexual activity, sexual disorders and associated help-seeking behavior among mature adults in five anglophone countries from the Global Survey of Sexual Attitudes and Behaviors (GSSAB). Journal of Sex \& Marital Therapy, 32, 331-342. doi:

\section{$10.1080 / 00926230600666469$}

National Institutes of Health, National Kidney and Urologic Diseases Information Clearinghouse. (2009, June). Erectile dysfunction (NIH Publication No. 09-3923). Retrieved from http://kidney.niddk.nih.gov/KUDiseases/pubs/ED/index.aspx

Nobre, P. J., \& Pinto- Gouveia, J. (2003). Sexual Modes Questionnaire: Measure to assess the interaction among cognitions, emotions, and sexual response. Journal of Sex Research, 40, 368-382. doi: 10.1080/00224490209552203

Pachankis, J. E. (in press). Developing an evidence-based treatment to address minority stress, mental health, and related health risks among gay and bisexual men. Clinical Psychology: Science and Practice.

Pachankis, J. E. (2007). The psychological implications of concealing a stigma: A cognitiveaffective-behavioral model. Psychological Bulletin, 133, 328-345. doi: 10.1037/00332909.133.2.328 
Pachankis, J. E., \& Goldfried, M. R. (2006). Social anxiety in young gay men. Journal of Anxiety Disorders, 20, 996-1015. doi: 10.1016/j.janxdis.2006.01.001

Perelman, M., Shabsigh, R., Seftel, A., Althof, S., \& Lockhart, D. (2005). Attitudes of men with erectile dysfunction: A cross- national survey. The Journal of Sexual Medicine, 2, $397-$ 406. doi: 10.1111/j.1743-6109.2005.20355.x

Preacher, K. J., \& Hayes, A. F. (2004). SPSS and SAS procedures for estimating indirect effects in simple mediation models. Behavior Research Methods, Instruments, \& Computers, 36, 717-731. doi:10.3758/BF03206553

Rathus, S. A., Nevid, J. S., Fichner-Rathus, L., Herold, E. S., \& McKenzie, S. W. (2007). Human sexuality in a world of diversity, $2^{\text {nd }}$ Canadian Edition. Toronto, ON: Pearson.

Ree, M. J., French, D., MacLeod, C., \& Locke, V. (2008). Distinguishing cognitive and somatic dimensions of state and trait anxiety: Development and validation of the State-Trait Inventory for Cognitive and Somatic Anxiety (STICSA). Behavioural and Cognitive Psychotherapy, 36, 313-332. doi: 10.1017/S1352465808004232

Rosen, R. C. (2001). Psychogenic erectile dysfunction: Classification and management. Urologic Clinics of North America, 28, 269-278. doi: 10.1016/S0094-0143(05)70137-3

Rosen, R. C., Fisher, W. A., Eardley, I., Niederberger, C., Nadel, A., \& Sand, M. (2004). The multinational Men's Attitudes to Life Events and Sexuality (MALES) study: I. Prevalence of erectile dysfunction and related health concerns in the general population. Current Medical Research and Opinion, 20, 607-617. doi:

$10.1185 / 030079904125003467$ 
Rosen, R. C., Riley, A., Wagner, G., Osterloh, I. H., Kirkpatrick, J., \& Mishra, A. (1997). The International Index of Erectile Function (IIEF): A multidimensional scale for assessment of erectile dysfunction. Urology, 49, 822-830. doi: 10.1016/S0090-4295(97)00238-0

Rosser, B. R. S., Metz, M. E., Bockting, W. O., \& Buroker, T. (1997). Sexual difficulties, concerns, and satisfaction in homosexual men: An empirical study with implications for HIV prevention. Journal of Sex \& Marital Therapy, 23(1), 61-73.

Rowen, C. J., \& Malcolm, J. P. (2003). Correlates of internalized homophobia and homosexual identity formation in a sample of gay men. Journal of Homosexuality, 43, 77-92. doi: 10.1300/J082v43n02_05

Sakheim, D. K., Barlow, D. H., Beck, J. G., \& Abrahamson, D. J. (1985). A comparison of male heterosexual and male homosexual patterns of sexual arousal. The Journal of Sex Research, 21, 183-198. doi:10.1080/00224498509551257

Sandfort, T. G., \& de Keizer, M. (2001). Sexual problems in gay men: An overview of empirical research. Annual Review of Sex Research, 12, 93-120. doi: $10.1080 / 10532528.2001 .10559795$

Shindel, A. W., Vittinghoff, E., \& Breyer, B. N. (2012). Erectile dysfunction and premature ejaculation in men who have sex with men. The Journal of Sexual Medicine, 9, 576-584. doi: 10.1111/j.1743-6109.2011.02585.x

Shires, A., \& Miller, D. (1998). A preliminary study comparing psychological factors associated with erectile dysfunction in heterosexual and homosexual men. Sexual and Marital Therapy, 13, 37-49. doi: 10.1080/02674659808406542 
Weinrich, J. D., Grant, I., Jacobson, D. L., Robinson, S. R., \& McCutchan, J. A. (1992). Effects of recalled childhood gender nonconformity on adult genitoerotic role and AIDS exposure. Archives of Sexual Behaviour, 21, 559-585. doi: 10.1007/BF01542256

Wilson, P. A., \& Yoshikawa, H. (2007). Improving access to health care among AfricanAmerican, Asian and Pacific Islander, and Latino lesbian, gay, and bisexual populations. In I. H. Meyer \& M. E. Northridge (Eds.), The health of sexual minorities: Public health perspectives on lesbian, gay, bisexual and transgender populations (pp. 607-637). Springer.

Wolitski, R. J., \& Fenton, K. A. (2011). Sexual health, HIV, and sexually transmitted infections among gay, bisexual, and other men who have sex with men in the United States. AIDS and Behavior, 15, 9-17. doi: 10.1007/s10461-011-9901-6

Wright, D. L., Aquilino, W. S., \& Supple, A. J. (1998). A comparison of computer-assisted and paper-and-pencil self-administered questionnaires in a survey on smoking, alcohol, and drug use. The Public Opinion Quarterly, 62(3), 331-353.

Yarber, W. L., Crosby, R. A., Graham, C. A., Sanders, S. A., Arno, J., Hartzell, R. M., ... \& Rothring, A. (2007). Correlates of putting condoms on after sex has begun and of removing them before sex ends: A study of men attending an urban public STD clinic. American Journal of Men's Health, 1, 190-196. doi: 10.1177/1557988307301276 